\title{
Arqueología de una aldea medieval y su espacio agrario: Villanueva de Santo Adriano (Asturias, noroeste de la península Ibérica)
}

\author{
Jesús Fernández Fernández
}

PALABRAS CLAVE: arqueología agraria, arqueología del paisaje, aldeas medievales, Asturias.

CÓDIGOS JEL: N53, N93, Y8, R14.

heste artículo se presentan los resultados del estudio arqueológico de una al-
dea de origen medieval, aún habitada, y su espacio agrario, localizados en As-
turias (noroeste de la península Ibérica). Con esta investigación se ha buscado dar respuesta a tres cuestiones que a día de hoy continuaban sin ser precisadas en esta área de montaña: ¿cuándo se produce la génesis de las aldeas?, ¿cómo? y, finalmente, ¿cómo se han ido transformando y evolucionado a través del tiempo?

Para alcanzar estos objetivos se han aplicando las metodologías tradicionales de la arqueología del paisaje, la historia rural, el estudio de la toponimia y la documentación, combinándolas con la datación y análisis diacrónico que permiten la arqueología de excavación, los datos paleoambientales y los estudios sedimentológicos. Todo el territorio aldeano se analizó como un único objeto de estudio, incluidas las áreas de producción agraria, que pasaron a formar parte prioritaria de la agenda de investigación. Esta aproximación nos ha permitido reconstruir la historia de una aldea y sus terrazgos desde su momento de formación en la Alta Edad Media (siglos VIII-XI) hasta el presente, e identificar los diferentes momentos de estabilidad y cambio en su paisaje. 
Creemos que más intervenciones como la desarrollada nos permitirán disponer de datos para la comparación y la creación de marcos generales de reflexión que conecten nuestra arqueología agraria con las discusiones a escala europea ya iniciadas décadas atrás.

\section{The archaeology of a medieval village and its agricultural context: Villanueva de Santo Adriano (Asturias, NW of the Iberian Peninsula)}

\section{KEYWORDS: agrarian archaeology, landscape archaeology, me- dieval villages, Asturias.}

\section{JEL CODES: N53, N93, Y8, R14.}

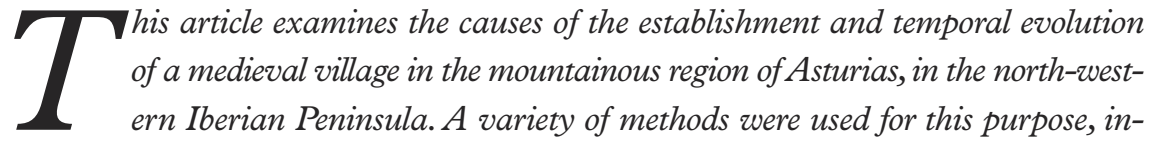
cluding landscape archaeology, rural history, the study of place names and written documents, combined with archaeological excavation, paleo-environmental analysis and sedimentological studies. A priority research point included the village surroundings that had been used for agricultural production; the whole area was analysed as one single object of study. This approach provided the possibility of identifying the various moments of stability and change in the landscape along with a reconstruction of the history of this still inhabited village and its agricultural milieu beginning in the Early Middle Ages (eighth to eleventh centuries). Further research along the lines developed here should provide data for comparison and connect this agricultural archaeology research with the broader European framework of discussion launched in past decades.

Recibido: 2015-09-07 - Revisado: 2015-12-24 - Aceptado: 2016-02-19

Jesús Fernández Fernández es investigador postdoctoral en la Universidad de Oxford, investigador asociado en el Instituto de Arqueología de la University College London y director de La Ponte-Ecomuséu. Dirección para correspondencia: La Ponte-Ecomuséu, $B^{\circ}$ del Sabil s/n, 33115 Villanueva de Santo Adriano (Asturias, España).C.e.:arqueoastur@gmail.com 


\section{INTRODUCCIÓN}

En el norte de la península Ibérica el estudio de las aldeas medievales y sus espacios agrarios está experimentando una importante renovación en las últimas décadas gracias a la incorporación de la arqueología. Este hecho tiene que ver con cambios dentro de la propia disciplina, con la progresiva ampliación de las temáticas de estudio y la superación de sus tradicionales enfoques monumentalistas (Barceló, 1988; Ballesteros et al., 2010). Los espacios irrigados, las acequias, las terrazas agrarias o las mismas aldeas son cada vez más objeto de análisis arqueológico, en la misma medida que los castillos, iglesias y monasterios. En todo este proceso ha influido notablemente la investigación de los despoblados, que nos ha permitido comprender mejor los patrones de asentamiento y la construcción de los paisajes medievales (Quirós, 2009, 2012; Vigil-Escalera, 2003, 2007, 2010). Esta renovación entronca con una larga tradición europea de estudios del mundo agrario (Guilaine, 1991), aunque en el norte peninsular la introducción de estas temáticas también ha sido más reciente (Ballesteros, 2002, 2003, 2010; Ballesteros \& Blanco, 2009; Ballesteros, Criado \& Andrade, 2006; Quirós, 2009, 2010, 2012;Vigil-Escalera, 2010; Ruiz del Árbol, 2005).

Por otro lado la amplitud y la profundidad de estas investigaciones ha sido geográficamente muy desigual. Sirva de ejemplo la zona rural y montañosa de Asturias, donde no ha faltado buena investigación desde las fuentes escritas, toponímicas, geográficas y paisajísticas (Torrente, 1986; Fernández Mier, 1999; Fernández Hevia \& Fernández Mier, 1994, 1998; García Fernández, 1988), pero sin una arqueología agraria plenamente desarrollada y con entidad propia. En estas zonas la documentación escrita indica una continuidad entre los espacios habitados en la Edad Media y las aldeas contemporáneas, por ello el censo de despoblados es escaso y su papel en el desarrollo de los estudios del mundo rural no puede ser equivalente al de otras regiones europeas. En este contexto la información arqueológica permanece en su mayor parte oculta bajo las actuales aldeas, razón por la que es necesario centrar la investigación en ellas si se pretende alcanzar una visión completa sobre la historia de las estructuras de poblamiento y los paisajes medievales, tal como se ha hecho en otras partes de Europa (Lewis, 2007). Esta situación obliga a diseñar una metodología adaptada a unas necesidades y preguntas de investigación específicas, en la que se lleva trabajando más de cinco años en Asturias (Fernández Mier, 2010; Fernández Mier et al., 2013; Fernández Fernández, 2014).

El objetivo de este artículo es presentar los resultados del estudio de una aldea asturiana de origen medieval que continúa actualmente habitada, trabajo que se ha realizado desde una perspectiva interdisciplinar y diacrónica. Con esta investigación se ha buscado dar respuesta a tres cuestiones que a día de hoy continuaban pendientes de ser precisa- 
das: ¿cuándo se produce la génesis de las aldeas y su terrazgo en estas zonas de montaña?, ¿Cómo se produce y qué procesos sociales están detrás? y finalmente, ¿cómo han evolucionado y se han ido transformando a lo largo del tiempo?

Para responder a este primer cuestionario, se han aplicado las metodologías tradicionales de la arqueología del paisaje, la historia rural, el estudio de la toponimia y la documentación, combinándolas con la datación y estudio diacrónico que permiten la arqueología de excavación, los análisis paleoambientales y los estudios sedimentológicos. Todo el territorio aldeano se analizó como un único objeto de estudio, de esta forma el «sitio arqueológico» se expandió a las áreas de producción agraria, que pasaron a formar parte prioritaria de la agenda de investigación con el objetivo de entender su proceso de construcción y transformación.

Por lo que sabemos, los principales rasgos y estructuras agrarias aldeanas parecen tener un origen medieval (Fernández Mier, 2010), período en el que se centrará principalmente este trabajo, aunque no se dejará de hacer referencias constantes, tanto a sus precedentes como a su evolución posterior a lo largo de la Edad Moderna y Contemporánea. No obstante, el estudio del paisaje y la evolución de estructuras resilientes como las aldeas no admite marcos cronológicos excesivamente restrictivos, que nos impedirían entender estos procesos de larga duración.

\section{FIGURA 1}

\section{Localización de Villanueva de Santo Adriano}

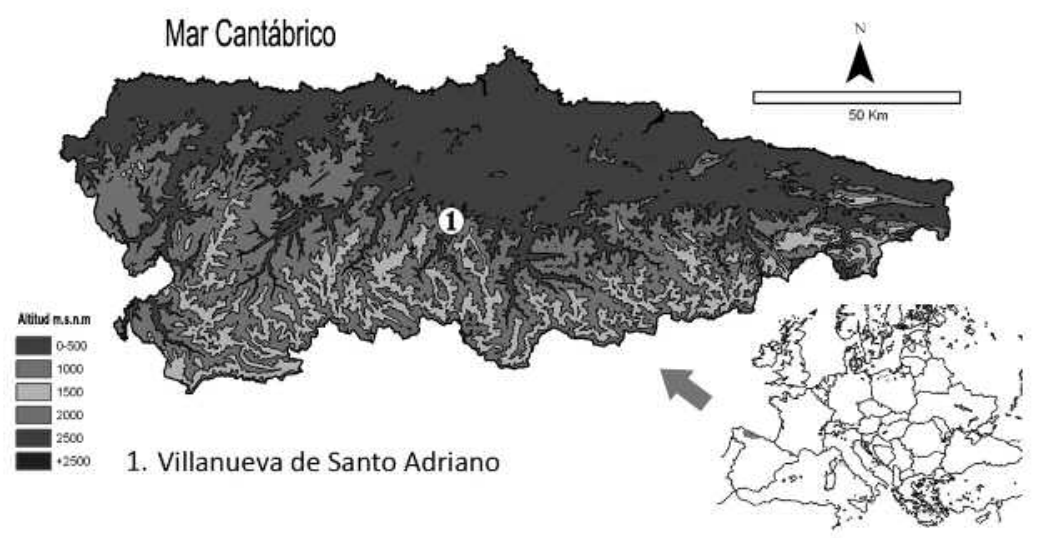

Fuente: elaboración propia.

La propuesta metodológica y los resultados aquí presentados son un punto de partida que puede servir para ser aplicado en otras aldeas de zonas de montaña con sistemas de po- 
blamiento en los que se ha dado una continuidad en el hábitat desde época medieval. Más intervenciones como la desarrollada nos permitirán disponer de datos para la comparación y la creación de marcos generales de reflexión que conecten nuestra arqueología agraria con las discusiones a escala europea ya iniciadas décadas atrás.

\section{LOCALIZACIÓNY METODOLOGÍA}

Nuestro objeto de estudio es Villanueva, un pequeño núcleo de hábitat concentrado (aproximadamente 50 habitantes en la actualidad) situado en un valle de la cordillera Cantábrica (zona de media montaña en el área central de Asturias, al noroeste de España), en las orillas del río Trubia (afluente del Nalón). El clima es oceánico suave, influido por la cercanía del mar, con precipitaciones abundantes todo el año y un paisaje muy accidentado que hace que la mayor parte de este pequeño territorio presente pendientes importantes y grandes desniveles.

Villanueva se asienta sobre la llanura aluvial, en el fondo del valle, y está compuesto por un total de ocho barrios: San Romano, Villanueva-El Puente, Traslaponte, El Carmen, La Arcellada, El Sabil, La Villa Fondera y Las Xanas (Figs. 2 y 4). A su alrededor se distribuyen diferentes espacios agrarios y ganaderos, siguiendo la clásica distribución concéntrica de las aldeas europeas de origen medieval, estando las parcelas dedicadas a la agricultura intensiva más próximas al caserío, seguidas de las erías (cultivos de reglamentación colectiva), los bosques y prados de siega en las laderas, ocupando una posición intermedia, y finalmente los aprovechamientos ganaderos de carácter extensivo y el monte bajo en las zonas más alejadas y elevadas. Los límites de la aldea y su terrazgo coinciden con los de la parroquia (San Romano, de unos $6 \mathrm{~km}^{2}$ ), sin existir actualmente otras unidades de hábitat importantes.

La forma tradicional de vida, de marcados rasgos preindustriales, se mantuvo hasta bien entrada la segunda mitad del siglo $\mathrm{xx}$, lo que ha facilitado la conservación de las estructuras agrarias, la distribución del parcelario y los aprovechamientos consuetudinarios, aunque su uso se ha ido transformando con la especialización de la ganadería extensiva de carne en la segunda mitad del siglo xx.

Para alcanzar los objetivos de esta investigación, se utilizaron diferentes materiales y métodos que se detallan a continuación. El estudio histórico se ha apoyado en varios documentos medievales en los que se encuentran referencias a la aldea. Proceden del archivo de la catedral de Oviedo, están fechados entre los siglos IX y XIv, y han sido publicados e incluso en algún caso sometidos a análisis de crítica documental (García Larragueta, 
1962; Fernández Conde \& Pedregal, 1995-1996; Fernández Conde, 1987; Ruiz de la Peña \& Beltrán, 2009). También ha sido consultada una parte de la documentación de época moderna, concretamente aquella que ha resultado más rica en información para la historia agraria, como las Respuestas Generales del Catastro del Marqués de la Ensenada (Fernández Fernández, 2014).

El estudio de la estructura actual del parcelario se ha llevado a cabo mediante el análisis de los planos catastrales actuales ${ }^{1}$; el contraste con el catastro histórico no indica transformaciones sustanciales de la estructura de la propiedad en las últimas décadas. La información relativa a los diferentes usos tradicionales del suelo y el vaciado de la toponimia se han obtenido mediante la realización de encuestas semiestructuradas a la población.

La información arqueológica se obtuvo mediante la realización de prospecciones superficiales y sondeos. Para realizar la prospección, se eligieron zonas que continúan teniendo un uso agrario y que por ello presentan mejores condiciones de visibilidad de objetos en superficie. En estos terrazgos se delimitaron áreas o unidades de prospección, generalmente coincidentes con los límites de la parcela elegida, en las que se realizaron batidas y se recogió una muestra aleatoria de material, principalmente cerámico. Se prospectaron dos tipos diferentes de áreas según su uso actual:

1. Área de cultivo intensivo dentro de la aldea. En este caso la parcela seleccionada fue un güertu (ITPr-ARC1), situado en el barrio de La Arcellada, con unas dimensiones aproximadas de $15 \mathrm{~m} \times 8 \mathrm{~m}$.

2. Áreas de cultivo más extensivo denominadas tradicionalmente veigas. Dos fueron las elegidas: La Güerta San Romano (código ITPr-GSR1), donde se prospectó una franja con unas dimensiones aproximadas de $50 \mathrm{~m} \times 7 \mathrm{~m}$, y La Veiga (ITPr-VEIG1), una de las principales erías de Villanueva. En este caso la franja estudiada fue de aproximadamente $87 \mathrm{~m} \times 5 \mathrm{~m}$.

La planificación de los sondeos arqueológicos se apoyó en los estudios previos de la toponimia, el estudio del parcelario y el estudio de la documentación escrita. Se llevaron a cabo, tanto en áreas cercanas al hábitat como en zonas productivas. En éstas últimas se seleccionaron espacios agrarios con muros de contención y superficies sin aterrazar. Las terrazas agrarias se seccionaron transversalmente incluyendo la parte superior e inferior de los taludes, aunque en algún caso resultó problemático por la profundidad alcanzada, por lo que la excavación se concentró exclusivamente en la sección transversal superior.

1. Accesibles en el portal virtual del catastro (http://www.catastro.meh.es/). 
Los sondeos realizados tuvieron generalmente pequeñas dimensiones (por lo general de $2 \mathrm{~m} \times 2 \mathrm{~m}$ ), aunque en cada caso tuvieron que adaptarse a las condiciones topográficas, aterrazamientos, etc. Posteriormente fueron ampliándose o no según la información arqueológica que proporcionaron. El de mayor tamaño se realizó en La Güerta San Romano $(10 \mathrm{~m} \times 3 \mathrm{~m})$. La excavación se llevó a cabo principalmente a través de métodos manuales, recurriendo también a los mecánicos en contadas ocasiones, dado que la información arqueológica es escasa y la excavación manual es la única que permite recuperar una mayor cantidad de materiales, especialmente importantes para comprender procesos tafonómicos en espacios agrarios.

La recopilación de información geoarqueológica y paleoambiental se ha llevado a cabo mediante medidas, descripciones y muestreos sistemáticos de las distintas unidades estratigráficas, obteniéndose así el material que posteriormente ha sido estudiado en el laboratorio.

\section{FIGURA 2}

\section{Sondeos realizados en el entorno del barrio medieval de San Romano} y su parcelario (Villanueva de Santo Adriano)

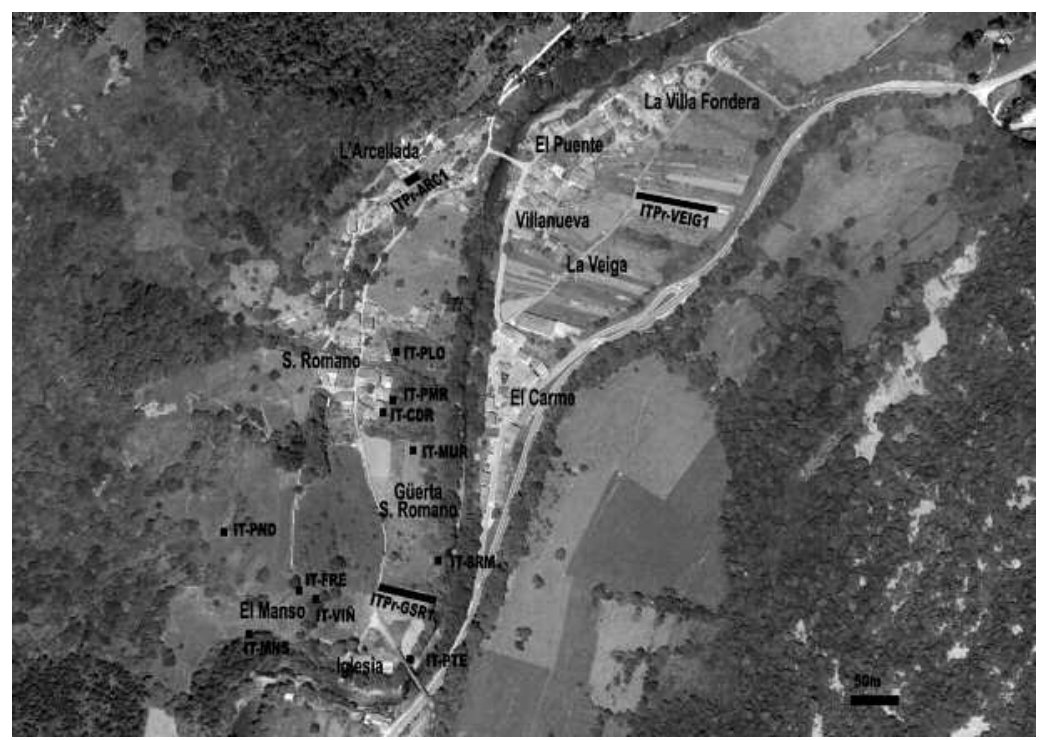

En la imagen se indican los códigos de intervención (IT) y las zonas de prospección arqueológica (ITPr). Fuente: elaboración propia sobre ortofoto (SIGPAC: http://sigpac.mapa.es/fega/visor/).

El análisis físico-químico de las muestras de polen se basó en el método clásico (Burjachs, López Sáez \& Iriarte, 2003). Para cada una de las muestras, se registraron unos doscientos granos de polen y un mínimo de 20 taxones, ya que esto permite inferencias estadística- 
mente fiables. El estudio de la taxonomía de polen y esporas se realizó siguiendo a Valdés, Díez y Fernández (1987), Moore, Webb y Collinson (1991), Reille (1999) y Beug (2004). Los palinomorfos no polínicos (NPP) se identificaron siguiendo el trabajo de Van Geel (2001).

La composición física de los suelos se estableció mediante el estudio de la distribución de tamaño de partículas minerales, mientras que los análisis químicos se realizaron a partir de los siguientes parámetros: $\%$ de $\mathrm{pH}, \%$ de materia orgánica, $\%$ de nitrógeno total, relación $\mathrm{C} / \mathrm{N}$ (carbono/nitrógeno), fósforo asimilable ( $\mathrm{pmm}$ ), calcio asimilable (pmm) y potasio asimilable $(\mathrm{pmm})^{2}$.

La datación por radiocarbono se realizó a partir de restos vegetales carbonizados y algún hueso. Posteriormente fueron calibradas con una precisión de $2 \sigma(95,4 \%$ de probabilidad) (Blaauw, 2010), utilizando el software de OxCal v 4.2.2 (Bronk Ramsey, 2009) con datos atmosféricos intcal09.14C (Reimer et al., 2009).

\section{RESULTADOS}

\subsection{La aldea a la luz de los primeros documentos}

Según consta en un documento conservado en la catedral de Oviedo (García Larragueta, 1962: 48-53), en el año 891 Alfonso III, rey de Asturias, y su esposa Jimena, fundan la iglesia-monasterio de Santo Adriano de Tuñón y la dotan con cuantiosos bienes, entre los que se encuentran varias villas. Una de ellas es San Romano -el topónimo se conserva como uno de los barrios de Villanueva-, que de esta forma pasa a integrarse en el dominio monástico, dentro de una política señorial y regia que en el siglo IX va a apoyarse en fundaciones como ésta para afianzar su autoridad e imponer una profunda reordenación de los territorios y sus poblaciones.

Siglos más tarde la influencia de la catedral de San Salvador de Oviedo en este valle irá ganando importancia hasta quedar integrado definitivamente en sus dominios. Será en un período de cuantiosas concesiones regias a las instituciones eclesiásticas, que se inician con Alfonso VI y cobran especial importancia en tiempos de Fernando II. Precisamente será este primer monarca quien, en un segundo documento fechado hacia el 1100 (García Larragueta, 1962: 313-315), entregará el monasterio y sus dominios a San

2. Un buen ejemplo del uso de este tipo de análisis aplicados a la arqueología agraria puede encontrarse en el trabajo de RUIZ DEL ÁRBOL (2005). 
Salvador, que los va a mantener bajo su jurisdicción hasta el siglo XVI. En él volvemos de nuevo a encontrar una referencia a San Romano dentro del elenco de villas donadas.

También en estos documentos encontramos algunas referencias a la toponimia menor de la aldea. Al estar acotando un territorio, se apoyan en sendas descripciones que aportan detalles sobre el paisaje y de vez en cuando permiten entrever alguna información sobre los diferentes grupos sociales o individuos que operan en él. Existe una linde coincidente entre el dominio monástico y el terrazgo de San Romano, lo que nos permite disponer, aunque sea indirectamente y solo en su mitad sur, de un primer y preciso contorno del territorio aldeano en la Alta Edad $\mathrm{Media}^{3}$, que se ha mantenido hasta la actualidad.

Los documentos a los que hemos hecho referencia fueron interpolados durante el obispado de Pelayo (1101-1130), lo que vierte serias dudas sobre su autenticidad, aunque un detallado estudio diplomático defiende que las partes en las que se encuentran las menciones a San Romano habrían formado parte de un texto original del siglo Ix que después se copiaría (Fernández Conde \& Pedregal, 1995-1996). En cualquier caso la fecha de principios del XII es válida, pudiendo así afirmarse que entonces San Romano era ya un núcleo habitado, sin descartar del todo que lo estuviese en el Ix.

En el siglo XIV encontramos de nuevo referencias a la aldea, cuya denominación cambia. Ya no es San Romano, sino Villanueva (Ruiz de la Peña \& Beltrán, 2009: 136-137), topónimo que conservará hasta la actualidad. Por entonces está integrada en un coto de obispalía que aglutina básicamente el mismo territorio que el antiguo monasterio de Tuñón y que habría pasado a ser una canonía rural. Esta nueva referencia aparece en el Libro de las Jurisdicciones de la catedral de Oviedo que en el siglo XIV trata de recoger un exhaustivo inventario de todos los derechos y rentas, tanto dominicales como jurisdiccionales, del obispado. Los pobladores de Villanueva tenían por entonces que satisfacer toda una serie de gravosas cargas señoriales ${ }^{4}$. Lo interesante de este documento es que diferencia entre estos vecinos y los de San Romano (çellero de San Román), que sopor-

3. Documento 1 (GARCía LARRAGUeta, 1962: 48-53): [...] per illo riuulum qui descendit de serande que dicunt Bulliera per aqua uerto de coto de penin per calellio de illa uaca [...]; Documento 2 (GARCÍA LARRAGUETA, 1962: 313-315): [...].per illa gallinera et per sembres et per merendrorios et per illa regaria de Citi Romaniz usque in flumine Trubia ubi dicunt Pelago Nigro ex alia parte per riuulum quem dicunt Bullera ad sursum et per quoto pennino et per illa aquilera et per penna de rege et per illa uerruga [...].

4. EnVillanueva deven pagar vodo, nunçio e manería, gallina e espalda de carnero cada uno (RUIZ DE LA PeÑa \& BeLtRán, 2009: 137). 
taban exigencias similares 5 . En el texto, la situación jurídica, determinada por el tipo de gravamen que cada colectivo vecinal debe satisfacer, es similar, luego la única razón que explica esta separación es la existencia de dos núcleos de población diferenciados.

A finales de este mismo siglo, marcado por una importante conflictividad entre la nobleza y la realeza en Asturias, se fundará en los límites de la parroquia, entre las aldeas deVillanueva y Proaza, la casa solariega de los Vázquez de Prada (García de Castro \& Ríos González, 1998), grupo subalterno de los máximos representantes de la nobleza local, los Bernaldo de Quirós, que a su vez eran vasallos del obispo de Oviedo y delegados de su autoridad en la comarca. Estos linajes aprovechan su condición de privilegio para incrementar sus patrimonios rústicos a costa de la privatización de espacios de uso colectivo. Del solar de Prada se desgajarán diferentes linajes emparentados, como los Muñiz Prada, que se asentarán en Villanueva (López Fernández, 1900), y reproducirán estos procesos de apropiación a menor escala a lo largo de la Edad Moderna dentro de una dinámica fomentada por la propia monarquía desde el siglo Xvi (Marcos, 1999).

La información de estos primeros documentos, aunque parca, nos permite al menos establecer una primera cronología relativa de los barrios principales de la aldea. Desde un núcleo primigenio denominado San Romano (siglos IX-XII), situado en la orilla oeste del río Trubia, se desarrolla una villa nueva en torno al siglo XIV, en su orilla este. En una secuencia general histórica, en un primer momento la aldea y su población formaron parte de una donación realizada por la realeza al monasterio de Tuñón entre los siglos IX-XII. Posteriormente pasaron a estar bajo el dominio de la catedral de Oviedo entre los siglos XII y mediados del XVI. En este momento la monarquía recupera su jurisdicción y la nobleza local, que ya reclamaba protagonismo político desde el siglo XIv, empieza a jugar un papel predominante con una mayor presencia en las aldeas a través de una serie de privatizaciones y transformaciones en los usos de los antiguos espacios agrarios que alcanzará en sus rasgos básicos la segunda mitad del siglo xx.

\subsection{El estudio del espacio habitado: morfología y toponimia}

El conjunto del espacio habitado presenta una organización multipolar, al tener cada uno de los barrios sus particularidades ${ }^{6}$. Del estudio de sus plantas y ordenación del caserío

5. El çellero de San Román. Todos los moradores deven pagar vodo, nunçio e manería e espalda e gallina cada uno (RUIZ de LA PEÑA \& BELTRÁN, 2009: 137).

6. La toponimia es poco informativa, aunque indica procesos de evolución del caserío que contribuyen a la interpretación general:Villanueva (barrio), en clara oposición a la villa vieja (San Romano), 
se pueden inferir datos complementarios para reconstruir la historia evolutiva del conjunto. Diferenciamos dos tipos claros de barrios: los alineados en torno a vías de comunicación y caminos (El Carmen, La Arcellada, Traslaponte) y aquellos otros que se componen de manzanas de casas con cierta estructura regular (San Romano), o de plano reticular (El Puente/Villanueva y La Villa Fondera).

Tomaremos como ejemplo El Puente ${ }^{7}$, que todavía conserva la denominación de Villanueva en una de sus partes, la más antigua (Fig. 2). El análisis de su planimetría permite concluir que existió una clara ordenación del espacio habitado (Fig. 3). Esta estructura recuerda, aunque a mucha menor escala, la observada en las polas y villas nuevas de mayores dimensiones, fundadas a partir del establecimiento de fueros urbanos entre los siglos XIII y XIV, fenómeno bien conocido y estudiado en Asturias por J. I. Ruiz de la Peña (1981a; Ruiz de la Peña, Beltrán \& Álvarez Fernández, 2006).

\section{FIGURA 3}

\section{Estructura reticular del barrio medieval de Villanueva-El Puente}

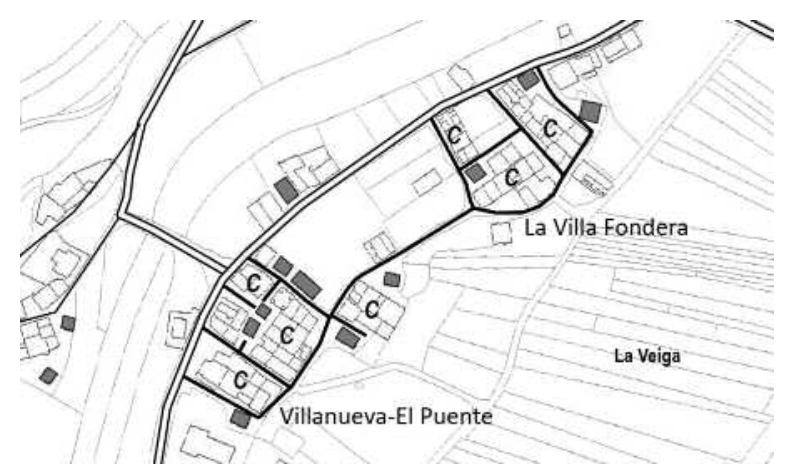

Se le atribuye una cronología del siglo xIV gracias a la documentación medieval. La Villa Fondera se extendería a partir de este barrio (véase en Fig. 4 su localización, al NE). La letra C indica la presencia de cuadrillas de casas y establos, y las cuadrículas grises se corresponden con hórreos y paneras. Las vías principales se resaltan en color negro. Los polígonos de perfil gris claro indican la actual estructura del parcelario.

Fuente: elaboración propia sobre plano catastral actual (http://www.catastro.meh.es/).

A partir de calles principales y secundarias se ordenaron las cuadrillas ${ }^{8}$ en las que se construyeron viviendas, adosadas las unas a las otras compartiendo muros medianeros. Estas

La Villa Fondera, como expansión de la villa nueva, o El Carmen, advocación de la capilla de origen moderno que está allí situada.

7. Se ha recogido también el topónimo La Ponte, aunque lleva décadas en desuso.

8. El término cuadrillas o cuadriellas es el utilizado en la documentación bajomedieval para referirse a los conjuntos de casas alineadas u ordenadas formando manzanas. 
cuadrillas tienen unas dimensiones similares en el frente (unos 12 metros en total y unos 30 metros de largo). Las manzanas de casas se articulan en torno a seis calles principales o caleyas, que crearon una malla ortogonal. Desde el camino principal (Camín Real deVentana) parten tres vías perpendiculares que conectaban con la zona principal de cultivo (La Veiga). Otras dos perpendiculares a éstas y paralelas al camino principal interconectaban la malla a la vez que cerraban el barrio perimetralmente. En las intersecciones de estas callejuelas se forman pequeñas plazas, que tradicionalmente se utilizaron para realizar la labor de desgranado de la escanda, y que reciben el nombre de eras. Cerca de ellas se construyeron los hórreos y paneras, que se insertan en la trama urbana de forma ordenada, como parte de un todo planificado e interconectado con el espacio de cultivo. Una primera expansión del barrio rompe esta estructura en su esquina noroeste, creando una nueva cuadrilla de casas en los antiguos espacios de cultivo y alterando la malla ortogonal.

Este tipo de planificación responde sin duda a una creación ex novo en época medieval, seguramente regulada por la existencia de algún tipo de fuero agrario y la presencia de autoridades como los departidores, que dirigían la creación de nuevas zonas habitadas en nombre del rey o señor (Ruiz de la Peña, Beltrán \& Álvarez Fernández, 2006). Dentro de los territorios bajo jurisdicción eclesiástica, en los que raramente se utilizaron fueros urbanos -sólo unos pocos casos y muy tardíos-, parece haber sido ésta la fórmula utilizada para la fijación de la población en el medio más rural (Ruiz de la Peña, 1981b). Podemos observar la plasmación material de un proceso de este tipo en el caso analizado y fecharlo cronológicamente de acuerdo con estos datos entre los siglos XIII y XIV. La destrucción de la «villa vieja» (S. Romano) como consecuencia de una inundación de carácter torrencial podría explicar la fundación de esta nueva aldea planificada, como se verá más adelante.

Observamos una estructura muy similar en el barrio de La Villa Fondera, cuya denominación da una pista clara de una fundación más tardía a partir de la villa nueva. En este caso el plano sigue un orden muy similar, pero con unas ampliaciones un tanto desordenadas de las cuadrillas, que han roto la forma reticular.

El barrio de San Romano, el más antiguo según la documentación y origen de la aldea, presenta una estructura similar a la de El Puente y La Villa Fondera, pues las casas se distribuyen por manzanas separadas por callejuelas o caleyas. A partir de este núcleo original de planta más o menos ordenada se extiende el caserío hacia el norte con una distribución lineal, siguiendo el curso del camino principal. Por ello, no transmite la misma imagen de orden y planificación que El Puente o laVilla Fondera. El barrio fue destruido por una inundación que arrasó por completo esta zona, como se mostrará más adelante. 
Posteriormente se produjo una concentración en ella de la nobleza, clero y elites campesinas de la aldea y lógicamente de nuevas construcciones, que iban a convivir con la presencia de cuadrillas de casas más humildes y establos. Se trata, en definitiva, de un barrio muy remodelado y transformado.

Los barrios de El Carmen, La Arcellada, Traslaponte y Las Xanas responden a un modelo de distribución lineal, articulado en torno a los caminos, que sería el resultado de la ocupación de nuevos solares en momentos de expansión demográfica partiendo de los núcleos más antiguos y principales, ya sin demasiado orden ni planificación.

\subsection{Las formas del paisaje, el terrazgo y la toponimia}

La parroquia estuvo dividida en diferentes unidades productivas y de paisaje. En este apartado iremos describiéndolas y atribuyéndoles una cronología relativa basándonos en lo que sabemos a partir de la documentación escrita, el estudio de la toponimia, su estructura y la información oral, etnográfica e histórica. Para ello, seguiremos un orden concéntrico, partiendo de los espacios más próximos a la zona habitada (Fig. 4).

\section{FIGURA 4}

Distribución del caserío de Villanueva y su espacio agrario inmediato

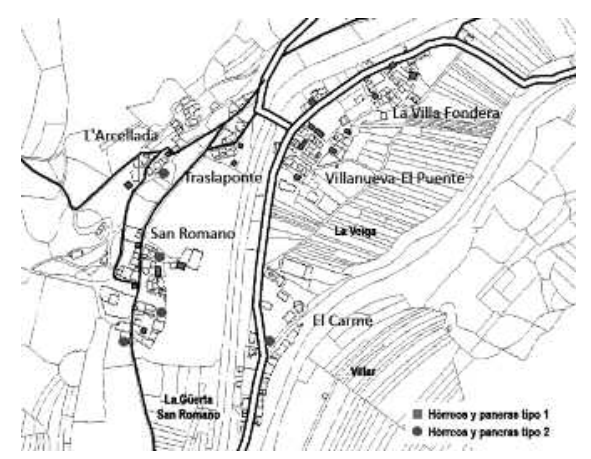

Las cuadrículas oscuras indican las zonas habitadas y las más claras la estructura del espacio agrario. Los hórreos y paneras del tipo 1 son los de rasgos más arcaicos y los de tipo 2 más evolucionados.

Fuente: elaboración propia sobre plano catastral actual (http://www.catastro.meh.es/).

Las estructuras agrarias más inmediatas a la aldea son un conjunto de parcelas individualizadas de pequeño y medio tamaño denominadas en lengua asturiana güertos y güertas. Están cercadas por muros de piedra, su uso no estaba regulado consuetudinariamente al ser de un único propietario, y ocupaban zonas intersticiales dentro de las áreas habitadas o muy próximas a ellas. Los güertos, de menor tamaño, estuvieron destinados al cul- 
tivo intensivo de hortalizas, que en muchos casos todavía mantienen. Las güertas, de dimensiones algo mayores, concentraron a mediados del siglo $\mathrm{xx}$ la siembra de la patata $\mathrm{y}$ el maíz, aunque se han ido convirtiendo posteriormente en pastizales y cultivos de frutales. En relación al espacio habitado, la presencia de güertos es más abundante en los barrios donde se observa una estructura menos planificada. Por otro lado, su morfología indica una aparición tardía con respecto al resto de los espacios agrarios, especialmente los de cultivo extensivo que están más cercanos a la aldea, a los que se superponen y de los que habrían sido sustraídos mediante privatizaciones. Las huertas de mayores dimensiones van a estar siempre asociadas a casas notables o de familias acomodadas y en mejores terrenos. El campesinado, de forma muy tardía (siglos XIX y XX), cercará sus huertas en el entorno de los barrios de suelos y calidades más pobres, como La Arcellada.

Sin duda, los principales suelos cultivables de la aldea fueron las erías, que en Villanueva reciben el nombre de veigas. Su función hasta la segunda mitad del siglo xx fue albergar el cultivo de carácter más extensivo, como la escanda, el maíz, el haba y la patata, principalmente. Tienen una extensión importante (entre 3 y 10 hectáreas) y el conjunto de parcelas está cercado perimetralmente. Las hazas, cada una de un propietario o llevador (persona que las lleva en renta), están separadas las unas de las otras por mojones hincados y tienen forma alargada y estrecha para favorecer el trabajo con la yunta de bueyes. Se trata de zonas rigurosamente reguladas por las costumbres consuetudinarias, con unas fechas de apertura y cierre de accesos (portiellas) que hasta hace pocas décadas se fijaban por acuerdo en asambleas vecinales. Están a distancias variables de la aldea, de 0 a 2 kilómetros. Las más importantes son La Veiga, La Veigabaxu, La Güerta San Romano, La Veiga Cericéu, y Villar, que han conservado su estructura y funciones hasta la segunda mitad del siglo xx. Otros espacios de estas características fueron privatizados ya en fechas muy tempranas. Es el caso de La Veiga de Buyera, una amplia pradera que pasó a ser propiedad de los Vázquez de Prada en torno al siglo XIV. Su morfología, análoga a la de las erías o veigas, y la estructura interna de sus parcelas así lo indican. Son posiblemente espacios creados bajo la presión de las roturaciones medievales, entre los siglos XII y XIII, cuando la aldea se expandió. Como veremos más adelante, la arqueología nos indica que fueron suelos dedicados al cultivo en su origen. Muchas de estas tierras se quedarán baldías durante la crisis demográfica del XIV, momento en que las elites nobiliarias aprovechen el argumento de su falta de uso para privatizarlas. Sin duda, Buyera y los terrenos anexos de Veganande y Las Segadas, que pasaron a engrosar el amplio patrimonio de los Vázquez de Prada, son un buen ejemplo de este proceso.

Más allá de las erías, a distancias variables de la aldea, desde un radio de $0,5 \mathrm{~km}$ hasta los $3 \mathrm{~km}$, encontramos las primeras zonas de uso ganadero, los prados, con un régimen de uso y propiedad similar al de huertos y huertas. Se trata de parcelas individuales, cer- 
cadas por muros de piedra, que habrían sido progresivamente ganadas para el aprovechamiento intensivo de pastos a los montes de uso colectivo a lo largo de la Edad Moderna. Su comunicación y accesos son clave para facilitar los trabajos de siega, mantenimiento, pastoreo, etc., por lo que se articularon en torno a las principales vías de comunicación y caminos. Cuando la distancia a la aldea es importante, a veces cuentan con un pequeño establo con henil, destinado a almacenar la cosecha estival y albergar el ganado en otoño-invierno. Este tipo de acotamientos empiezan a cobrar protagonismo a medida que la ganadería gana importancia con respecto a la agricultura, especialmente a partir del siglo XIV cuando las elites encuentran en este sector económico una fuente de ingreso. Este proceso se hará más intenso en los siglos XVII y XVIII. Como ejemplo, en Valdarrozas, topónimo que indica un aprovechamiento previo de carácter extensivo (basado en las rozas del monte bajo), la parcela principal, de más extensión y calidad, perteneció según la denominación popular al conde (linaje de los Vázquez de Prada y descendientes). Cerca encontramos el topónimo Mendesurias $^{9}$, que indica la participación de otros grupos sociales en esta privatización del monte de uso colectivo. La ganadería cobrará especial importancia en los siglos XIX y XX, cuando la industrialización incremente la demanda de carne en las ciudades, coincidiendo con un importante crecimiento demográfico. Será en este período cuando se construyan muchas de las cabañas que encontramos en el entorno de espacios comunales y se gane terreno y privaticen parcelas. En este caso los protagonistas serán ya los propios campesinos. En la estructura de la aldea vemos claramente cómo los edificios dedicados a la ganadería cobran importancia y, a medida que se construyen, rompen la estructura de los barrios adentrándose incluso dentro de espacios tradicionalmente más reglamentados y restringidos, los dedicados al cultivo.

Más allá de los prados encontramos las morteras comunales. Su sistema de gestión es muy similar al de las veigas o erías, combinando un uso privado dentro de marcos de organización y aprovechamientos colectivos. Según el dato etnográfico, su función principal fue la producción de hierba de siega en verano y de pasto en otoño y primavera. La única mortera comunal de Villanueva es Caúzo, un espacio clave en el acceso a las rutas ganaderas y los montes. En verano permanecía cerrada entre el 8 de mayo y el 31 de septiembre para la producción de heno. El resto del tiempo se derrompia (se abrían sus portiellas), para que quedase conectada al terreno común que la rodeaba y que todo el ganado de la parroquia aprovechase el pasto. Como ya indicamos, el proceso de privatización

9. El primero de los elementos que forman este topónimo parece ser un nombre: $M e(n e) n d o$ o, más probablemente, $\mathrm{Me}(n e) n d e$, reducido al quedar átono en composición, y el segundo un patronímico de Suarius Suero, que sería Suariz, Suares. La generalización de los apellidos se dará a partir de los siglos X-XI, por lo que para la formación de este tipo de topónimos se podría fijar una cronología post quem en esos siglos. 
de la mortera de Caúzo parece ser muy tardío y estuvo protagonizado por campesinos. Se puede apreciar en la morfología actual la superposición de cierres sobre el antiguo espacio de uso colectivo, aunque al contrario que en otros casos de Asturias, donde las morteras comunales se privatizaron íntegramente, en Villanueva este proceso no llegó a finalizarse, perviviendo hasta hoy día una zona de usos semicolectivos y régimen mixto de propiedad.

\section{FIGURA 5}

Aldea, límites de la parroquia, espacios agrarios y usos tradicionales del suelo

hasta c. 1950

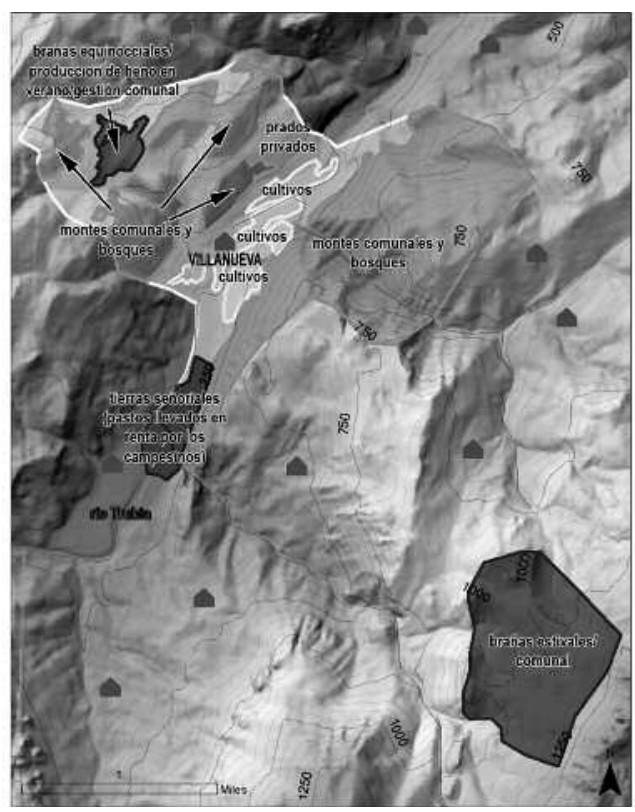

Fuente: elaboración propia.

También encontramos otro tipo de morteras, en este caso de propiedad señorial. Son espacios de uso ganadero que se regulaban de forma similar a las comunales con la diferencia de que se pagaba una renta por porción de terreno, según se pudo constatar mediante encuestas. Cada campesino llevaba una o varias parcelas individualizadas y separadas del resto por mojones (muñones), que aún reciben actualmente la denominación de ducados, en referencia a una unidad monetaria, al contrario que en las erías, donde para este tipo de divisiones se han utilizado tradicionalmente expresiones comunes (piezas, tiras, estayas, etc.). Las principales morteras señoriales son Buyera y las Segadas, que pertenecieron a los Vázquez de Prada y su parentela desde el siglo XIV. 
En los meses de verano, cuando las morteras comunales estaban cerradas, el ganado se trasladaba a la braña estival de Andrúas, puerto compartido con otras parroquias próximas, como Serandi, San Martín oVillamexín y algunas parroquias del concejo de Quirós (Bermiego y La Rebollada). La primera referencia escrita a este espacio ganadero la encontramos en fecha muy temprana (siglo XII) en un documento al que ya hemos hecho referencia (García Larragueta, 1962: 52) que indica el interés del señorío de la catedral de Oviedo en controlar estos pastos estivales ${ }^{10}$. En el Puertu de Andrúas el pueblo de Villanueva poseía una cabaña propia, denominada corro, para guardar terneros y pernoctar, que todavía se conserva y da nombre al lugar (cabaña de Villanueva). Es un ejemplo único de arquitectura comunal, con falsa bóveda por aproximación de hiladas cubierta de trozos de tierra con césped (tapín) y planta cuadrangular (Fig. 6). Esta estructura se integra en un conjunto de corros individuales de otras aldeas y restos de estructuras que solo conservan sus líneas de cimentación y que evidencian distintas ocupaciones a lo largo del tiempo.

\section{FIGURA 6}

\section{Cabaña comunal de Andrúas}

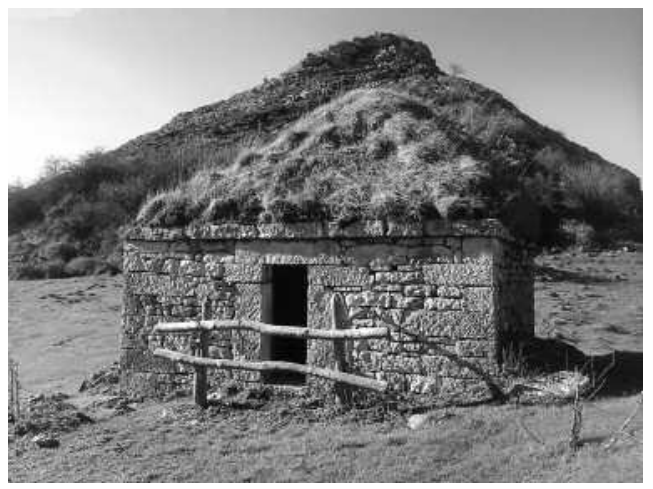

Espacio ganadero ya mencionado en la documentación del siglo XII.

Fuente: fotografía del autor.

Esta serie de informaciones documentales, toponímicas y morfológicas nos ayudan a entender la aldea y su agrosistema tradicional, pero la imprecisión cronológica que atraviesa todo este apartado no puede resolverse si no es recurriendo a la fuente arqueológica. Para ello, se realizaron diferentes intervenciones (prospección y excavación de sondeos), tanto en zonas cercanas al espacio habitado como en el terrazgo circundante. En el siguiente apartado presentamos los resultados obtenidos.

10. Addicemus eciam ecclesie uestre busta pernominata in territorio Asturiensi id est in monte Aramo...et bustu quod dicunt Pando de Andruas [...] 


\subsection{Análisis arqueológico}

\subsubsection{Prospección}

En la Güerta San Romano (código ITPr-GSR1; Fig. 2) se recuperaron un total de 17 fragmentos cerámicos en superficie, de los cuales 16 son galbos y 1 un borde. Por cocciones, predominan las mixtas (11), sobre todo el grupo de cocción oxidante con postcocción reductora (6). Por cronologías, ha podido establecerse un conjunto muy claro de cerámicas medievales, con decoraciones peinadas y formando retículas (8, lo que representa casi la mitad de la muestra); otro grupo, que no ha podido ser asignado cronológicamente $(4,23 \%)$, aunque se trata de facturas preindustriales; y un último conjunto, también claro, de cerámicas moderno-contemporáneas $(5,24 \%)$, donde predominan los fragmentos de platos vidriados procedentes del alfar ovetense de Faro ${ }^{11}$. Desde un punto de vista tafonómico, se trata de fragmentos de pequeñas dimensiones (el de mayor tamaño de unos $4,5 \mathrm{~cm}$, el de menor tamaño de unos $1,5 \mathrm{~cm}$ ) muy rodados, lo que atribuimos al uso continuado del arado.

En otra de las parcelas prospectadas, La Veiga (ITPr-VEIG1), se recuperaron un total de 30 fragmentos cerámicos, de los cuales 20 son galbos, 8 bordes y 2 bases. Por cocciones, predominan las oxidantes (17), seguidas de las mixtas (7), todas de cocción oxidante con postcocción reductora, y finalmente reductoras (6). Por cronologías, destaca claramente el grupo moderno-contemporáneo (23, el 76\%), con predominio de fragmentos de platos vidriados, lozas y porcelana. Solamente ha podido identificarse un único ejemplo de cerámica con decoración peinada que puede ser claramente atribuido al período medieval $(1,3 \%)$, mientras que un conjunto de fragmentos de cocción reductora sin decoración no ha podido ser asignado con claridad a ninguna cronología (6, el 20\%), en cualquier caso sería preindustrial. Desde un punto de vista tafonómico presentan unas características similares a las observadas ya en otras zonas de trabajo agrícola extensivo, fragmentos rodados y de pequeñas dimensiones (el de mayor tamaño de unos $4,5 \mathrm{~cm}$, el de menor tamaño de unos $1,3 \mathrm{~cm}$ ).

La otra unidad de prospección seleccionada (ITPr-ARC1) es una parcela ubicada en una ladera, en la que se tuvo que construir un importante aterrazamiento para hacerla cultivable. En ella se recuperaron un total de 14 fragmentos cerámicos. En este caso no aparecen cerámicas medievales, solamente moderno-contemporáneas. Predominan las coc-

11. Faro es una localidad próxima a la ciudad de Oviedo, donde se ha desarrollado una importante labor alfarera desde la Edad Media hasta bien entrado el siglo Xx, que ha dado lugar a determinados tipos de decoraciones y formas propias. 
ciones oxidantes ( 7 fragmentos, entre los que se incluyen 3 lozas, un galbo decorado del alfar de Vega de Poja y 3 bordes de platos con vidriado tipo Faro), seguidas de las mixtas (5, grupo de cocción oxidante con postcocción reductora, cerámicas negras de Faro) y reductoras ( 2 fragmentos). Respecto de la tafonomía, en general se trata de fragmentos más grandes y menos rodados que los recuperados en las veigas (el de mayor tamaño unos 11 $\mathrm{cm}$, el de menor, unos 2,5 cm), que relacionamos con la ausencia de uso del arado en este tipo de parcelas dedicadas tradicionalmente a la agricultura intensiva de hortalizas.

A estos datos se suman los que se recuperaron durante la realización de varios sondeos de seguimiento arqueológico en una obra pública llevada a cabo recientemente (Montes, 2015). Una primera información de interés procede de la pradera de Buyera, donde se documentó un lote de cerámicas de cronología medieval, lo que contrasta con la ausencia de cerámicas modernas. Al contrario, en La Veiga de Cericéo, el informe apunta la ausencia de cerámicas medievales, que contrasta con su presencia en otras erías.

En conclusión, la prospección superficial nos aporta unos primeros datos, aunque muy limitados, sobre los usos de los espacios de trabajo en el entorno de la aldea a lo largo de la historia. Los indicadores utilizados, como la presencia o no de cerámica en superficie -que puede relacionarse con el aporte de residuos durante las tareas de estercolado- y su estado de conservación solamente permiten inferir información relativa a las prácticas agrarias. Como ejemplo, la abundancia de cerámica medieval, moderna y contemporánea, muy fragmentada y rodada en la Güerta San Romano, la interpretamos como una prueba de la continuidad de un aprovechamiento agrario de carácter extensivo. Sin embargo, en La Veiga la escasez de cerámica medieval indica un proceso más tardío, en algún momento en que se está produciendo el cambio de estilos decorativos, con la desaparición de las incisiones peinadas a finales de la Edad Media. ¿Cuál fue la función anterior de este espacio? El registro de superficie muestra aquí sus múltiples limitaciones. Casos como el de Cericéu podrían indicar procesos de roturación durante los tirones demográficos del XVI o del XVIII. Y en el caso de Buyera ocurre lo contrario: solamente se conserva cerámica medieval, lo que puede interpretarse como un cese de la actividad agraria en algún momento durante o tras la Edad Media. Este cambio puede relacionarse con la privatización del espacio agrario por parte de la familia Vázquez de Prada en el siglo XIV, coincidente con una importante contracción demográfica en toda Europa. En el caso de los huertos se confirma también una menor antigüedad. Parecen haber sido ganados privatizando zonas que tendrían anteriormente un uso colectivo, no agrario por su pendiente, y que solamente pudieron cultivarse aterrazando el terreno. La menor fragmentación y grado de rodamiento del material cerámico procedente de estos huertos lo atribuimos a un tipo de cultivo en el que no se utiliza el arado, sino aperos de labranza, que profundizan y remueven menos en el suelo. 
TABLA 1

Resultados de la prospección arqueológica de espacios agrarios

\begin{tabular}{lcccc}
\hline $\begin{array}{l}\text { Topónimo-espacio } \\
\text { agrario }\end{array}$ & $\begin{array}{c}\text { Fragmentos } \\
\text { recogidos }\end{array}$ & $\begin{array}{c}\text { Cerámica medieval y porcentaje } \\
\text { respecto del conjunto }\end{array}$ & $\begin{array}{c}\text { Cerámica moderna } \\
\text { y contemporánea }\end{array}$ & $\begin{array}{c}\text { Cronología } \\
\text { uso agrario* }\end{array}$ \\
\hline Güerta de San Romano & 17 & Sí (47\%) & Sí & Edad Media-actualidad \\
La Veiga & 30 & Sí $(3 \%)$ & Sí & Edad Media tardía-actualidad \\
Buyera & 11 & Sí $(100 \%)$ & No & Edad Media \\
Güertu L'Arcellada & 14 & No & Sí & Edad Moderna-actualidad \\
Cericéu & 0 & No & No & ¿Edad Moderna?-actualidad \\
\hline
\end{tabular}

*Basada en los resultados de la prospección.

Fuente: elaboración propia.

Estos primeros análisis superficiales aportan información interesante y permiten establecer unas primeras hipótesis de trabajo y cronologías relativas sobre los parcelarios, aunque con importantes limitaciones. La única forma de poder precisar más es recurrir a la excavación arqueológica y al análisis de las secuencias estratigráficas mediante muestreos que permitan identificar diacrónicamente diferentes usos y funciones del espacio, y no sólo informar sobre prácticas agrarias. Para ello se realizaron nueve sondeos en parcelas del entorno del barrio de San Romano (Fig. 2). A continuación presentamos una síntesis de los resultados obtenidos.

\subsubsection{Excavación de los espacios agrarios: La Güerta San Romano, un espacio utilizado desde la Prehistoria}

En este espacio y su entorno se realizaron seis sondeos (IT-SRM, IT-PTE, IT-PMR, ITCDR e IT-MUR) ${ }^{12}$ (Figs. 2 y 7), que ya han sido pormenorizadamente descritos en otras publicaciones (Fernández Fernández, 2014a), por lo que nos limitaremos aquí a realizar una síntesis interpretativa. En ellos hemos diferenciado las siguientes fases o episodios arqueológicos que a continuación pasamos a describir.

Fase 1: formación de la terraza fluvial y primeras ocupaciones en la Prehistoria. En el muro de todos los sondeos citados se encuentran los depósitos aluviales que el río iría depositando a lo largo del Pleistoceno. Un fragmento de materia vegetal carbonizada procedente del sondeo IT-PMR (base de la UE10b, Fig. 8) ha aportado una datación en torno a $40.000 \mathrm{BP}$ e indica la formación de los primeros suelos sobre la terraza fluvial. Otra datación procedente del techo de este primer nivel aporta otra fecha de $4.000 \mathrm{BP}$, que coin-

12. El tercer sondeo realizado (IT-PLO) no dio resultados positivos. 
cide con el Neolítico final, aunque no podemos asociarla a ningún tipo de material arqueológico. El dato no desentona con las fechas que confirman la existencia de asentamientos estables del Neolítico final en el entorno de otras aldeas, como Vigaña d'Arcéu (Belmonte, Asturias) con esas mismas cronologías (Fernández Fernández, 2014a; Fernández Mier et al., 2014). A esta información se suma la recuperada durante los trabajos de seguimiento arqueológico anteriormente citados (Montes, 2015), que en esta parcela rescataron algunos fragmentos de cerámicas prehistóricas (posiblemente de la Edad del Hierro), dato que viene a confirmar el sentido de nuestras dataciones y una presencia humana continuada en la vega desde momentos muy tempranos.

\section{FIGURA 7}

\section{Localización de los sondeos más próximos al área habitada (San Romano)}

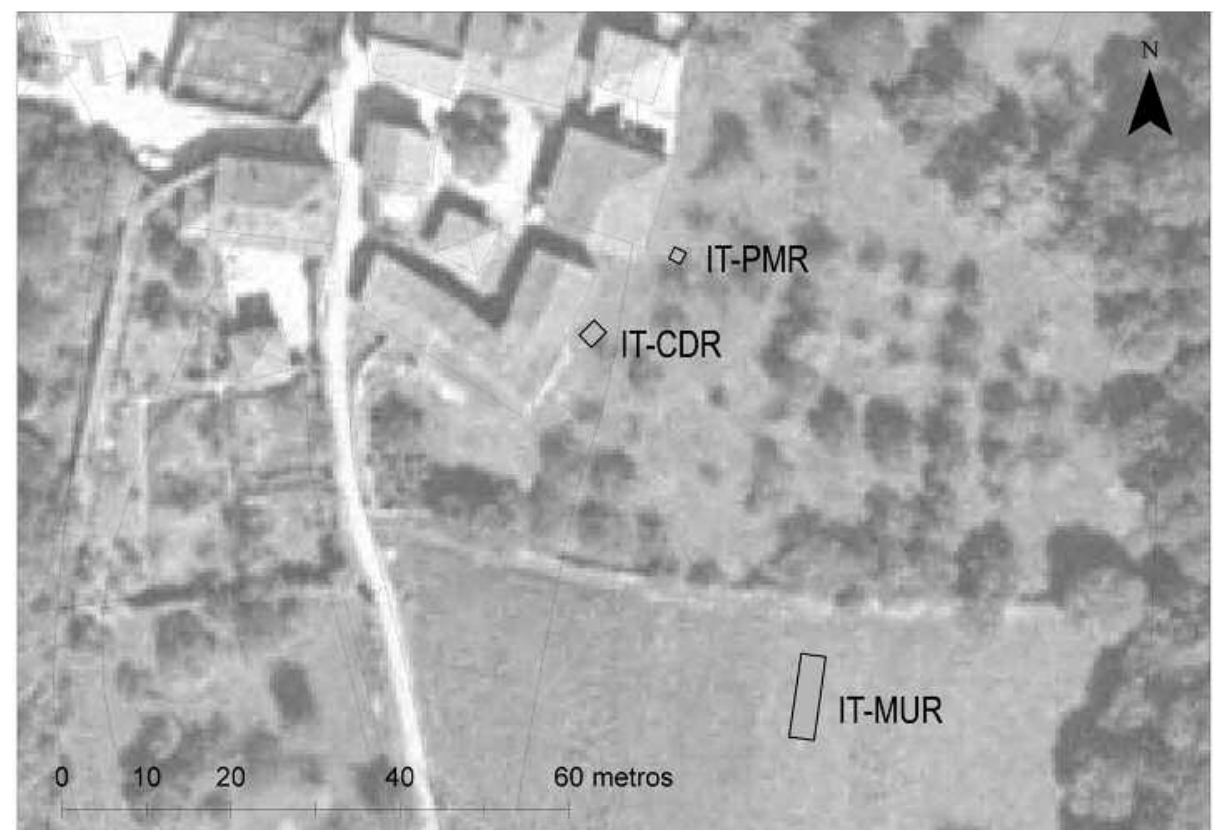

Fuente: elaboración propia sobre ortofoto (SIGPAC) y mapa topográfico 1:5000.

Fase 2: época romana. Sobre estos primeros suelos prehistóricos de cronología pleistocena-holocena, se documenta un primer horizonte edáfico claramente definido (UE013 en la IT-CDR y UE010a en la IT-PMR) en el que se pudieron recuperar algunos fragmentos de cerámicas de tradición romana (cerámicas comunes y terra sigillata hispánica), que atribuimos cronológicamente a época altoimperial. Los escasos restos de fauna recuperados (vaca y ovicaprino) y los análisis químicos del suelo indican un uso no agrario de este espacio por la baja relación del C/N. Los análisis polínicos corroboran esta in- 
formación y nos hablan de un espacio muy deforestado, con abundantes espacios abiertos de vegetación herbácea y una importante presión sobre el bosque. No aparecen cereales y dentro de las especies arbóreas tienen cierta importancia el castaño y el nogal, que interpretamos como cultivos. Todo ello viene a sugerir la presencia de espacios económicos adehesados de aprovechamiento ganadero y frutícola, próximos a algún asentamiento tipo granja o casal, que completarían el variado panorama ambiental intuido a partir de los resultados de otras excavaciones, como la de la villa de Veranes en Gijón (Fernández Ochoa \& Gil Sendino, 2007), y que se corresponde con lo observado en regiones limítrofes, como el País Vasco o la Meseta (Quirós \& Vigil-Escalera, 2006). Durante los citados trabajos de seguimiento arqueológico (Montes, 2015), se descubrió una estructura que se ha interpretado como algún tipo de drenaje. Está excavada sobre suelos donde se encuentran materiales prehistóricos y cubierta por niveles modernos y posiblemente medievales. A falta de más datos para contextualizar con precisión, y como hipótesis, parece tratarse de algún elemento asociado a este aprovechamiento de fondo de valle en época romana.

\section{FIGURA 8}

\section{Perfiles estratigráficos de sondeos realizados cerca del actual núcleo aldeano}
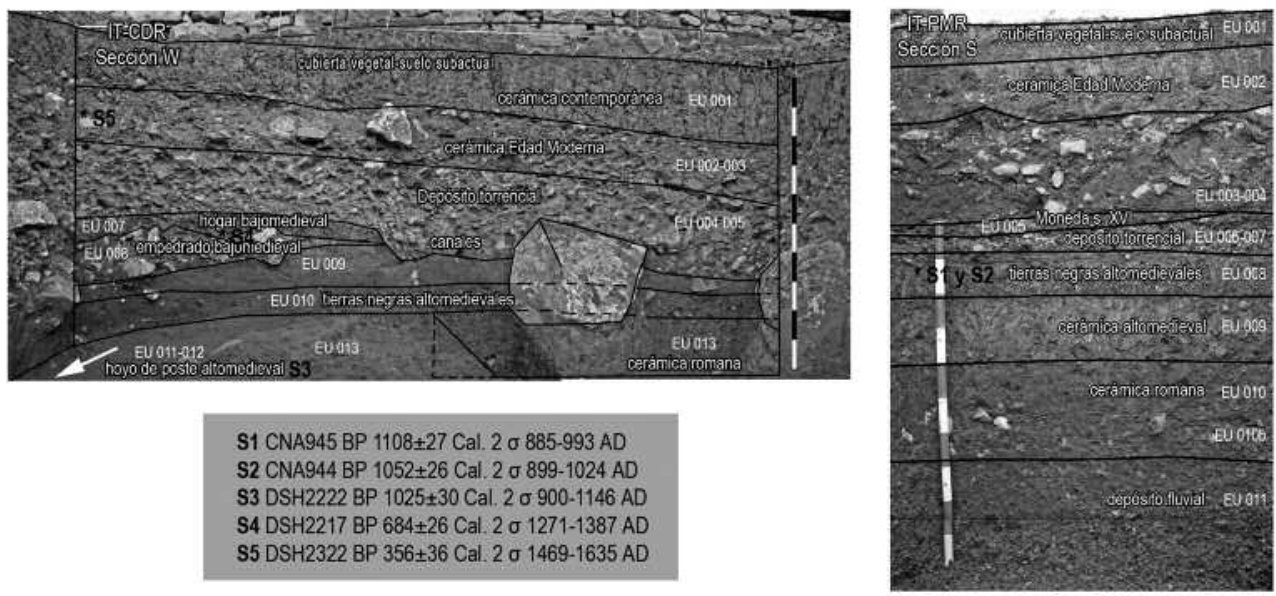

La sigla del sondeo se muestra en la parte superior izquierda. En la tabla inferior se indican las dataciones absolutas obtenidas con una $\mathrm{S}$ y una clave numérica que remite al código de laboratorio de la Tabla 2: S1= CNA945; S2=CNA944; S3=DSH2222; S4=DSH2217; S5=DSH2322.

Fuente: elaboración propia. 
TABLA 2

Dataciones radiocarbónicas

\begin{tabular}{|c|c|c|c|c|c|}
\hline Código laboratorio & Material & Código intervención (sondeo) & UE & Fecha $\mathrm{C}^{14} \mathrm{BP}$ & Edad calibrada $(2 \sigma)$ \\
\hline \multirow[t]{2}{*}{ CNA824 } & Carbón & MNS & 5 & $1070 \pm 35$ & $894-928(24 \%)$ \\
\hline & & & & & $934-1021(76 \%)$ \\
\hline CNA825 & Hueso & MNS & 5 & $925 \pm 30$ & $1026-1177(100 \%)$ \\
\hline \multirow[t]{5}{*}{ DSH2218 } & Carbón & MNS & 5 & $1028 \pm 31$ & $899-919(4 \%)$ \\
\hline & & & & & $951-956(1 \%)$ \\
\hline & & & & & $961-1043(93 \%)$ \\
\hline & & & & & $1104-1118(1 \%)$ \\
\hline & & & & & $1143-1146(1 \%)$ \\
\hline \multirow[t]{2}{*}{ DSH2215 } & Carbón & MNS & 6 & $661 \pm 33$ & $1276-1324(50 \%)$ \\
\hline & & & & & $1345-1393(50 \%)$ \\
\hline \multirow[t]{2}{*}{ DSH2232 } & Carbón & MNS & 7 & $1212 \pm 32$ & $692-749(16 \%)$ \\
\hline & & & & & $764-891(84 \%)$ \\
\hline \multirow[t]{2}{*}{ DSH2217 } & Carbón & $\mathrm{CDR}$ & 7 & $684 \pm 26$ & $1271-1311(70 \%)$ \\
\hline & & & & & $1359-1387(30 \%)$ \\
\hline \multirow[t]{4}{*}{ DSH2222 } & Carbón & CDR & 11 & $1025 \pm 30$ & $900-917(2 \%)$ \\
\hline & & & & & $966-1044(95 \%)$ \\
\hline & & & & & $1101-1119(2 \%)$ \\
\hline & & & & & $1143-1146(1 \%)$ \\
\hline DSH2322 & Carbón & $\mathrm{CDR}$ & 3 & $356 \pm 36$ & $1469-1635(100 \%)$ \\
\hline CNA826 & Carbón & SRM & 2 & $995 \pm 40$ & $982-1155(100 \%)$ \\
\hline \multirow[t]{2}{*}{ CNA827 } & Carbón & PND & 1 & $310 \pm 30$ & $1487-1604(75 \%)$ \\
\hline & & & & & $1608-1649(25 \%)$ \\
\hline CNA828 & Carbón & PTE & 2 & $330 \pm 30$ & $1477-1642(100 \%)$ \\
\hline \multirow[t]{3}{*}{ CNA944 } & Carbón & PMR & 8 & $1052 \pm 26$ & 899-919 (9\%) \\
\hline & & & & & $950-957(1 \%)$ \\
\hline & & & & & $961-1024(89 \%)$ \\
\hline CNA945 & Carbón & PMR & 8 & $1108 \pm 27$ & $885-993(100 \%)$ \\
\hline
\end{tabular}

Fase 3: los primeros campos altomedievales. Sobre los suelos de cronología romana localizamos unos primeros indicios de actividad en algún momento previo al siglo $\mathrm{x}$ (UE 009, IT-PMR). Se trata de un primer suelo de cultivo, como así indican los análisis químicos del suelo, con abundancia de materia orgánica y un incremento considerable de la relación carbono/nitrógeno $(9,1)^{13}$. El polen de cereal aparece representado en por-

13. FERnÁndEZ FERnÁndez (2014a: 369). 
centajes del 3,9\%, que implicarían su cultivo in situ (López Sáez \& López Merino, 2005). La cobertura arbórea muestra cierta recuperación respecto del período romano (porcentaje de árboles del orden del 30\%), aunque ya no hay presencia del nogal (se incrementa el castaño). La cultura material se compone de restos de cerámicas principalmente negras y grises (Fig. 9), similares a otras series localizadas en diferentes contextos arqueológicos altomedievales de Asturias (Requejo, 2004). No disponemos de ninguna datación absoluta de este suelo de cultivo por falta de muestras de calidad, pero fue cubierto por un nivel fechado en el siglo $\mathrm{x}$, que posteriormente describiremos.

A esta fase se corresponderían también una serie de estructuras negativas y un hoyo de poste excavados sobre los primeros horizontes de época antigua (UE012, IT-CDR) y que fueron amortizados por rellenos de cronología altomedieval (siglos X-XI; UE011, ITCDR) (Tabla 2: DSH2222). Estas estructuras negativas indican la presencia de algún tipo de estructura vertical, bien sea doméstica, bien algún tipo de construcción complementaria a la actividad agraria anteriormente descrita (hórreos, graneros, cierres para el ganado, etc.), que marcaría en cualquier caso el nacimiento de un asentamiento campesino que continuará hasta la actualidad.

\section{FIGURA 9}

\section{Cerámica medieval recuperada en diferentes unidades estratigráficas y sondeos}
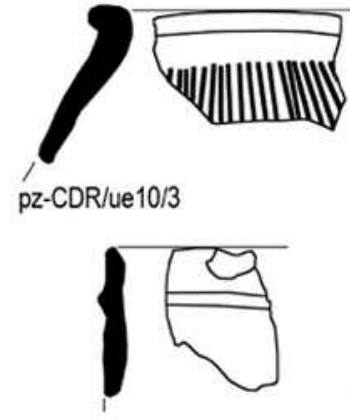

pz-CDR/ue10/6

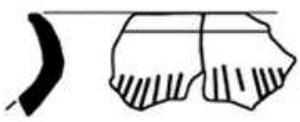

pz-PMR/ue3/4

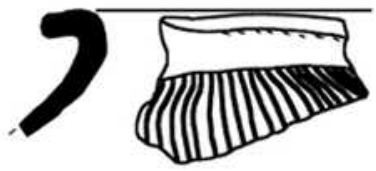

pz-PMR/ue8/1

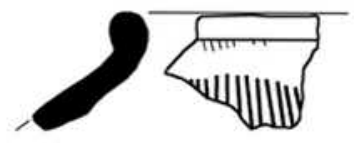

pz-PMR/ue8/3

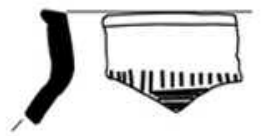

pz-PMR/ue9/1

Las tres primeras letras de cada sigla indican el nombre de la intervención (localizadas en la Fig. 2), seguida de la UE (Fig. 8) y el número de pieza.

Fuente: elaboración propia. 
Fase 4: ¿Un primer crecimiento de la aldea altomedieval? Sobre estos primeros indicios de actividad agraria y presencia de estructuras se localizan unos suelos negruzcos de similares características a las dark earth (Macphail \& Linderholm, 2004), que se han fechado en torno al siglo x (UE010 y UE011 de la IT-CDR10 y UE008 de la IT-PMR10; muestras DSH2222 y CNA944-CNA945 respectivamente) (Tabla 2). La bibliografía especializada asoció en un principio la presencia de este tipo de tierras a entornos urbanos tardoantiguos y altomedievales, aunque posteriormente el uso del término se extendió también a asentamientos rurales de cronologías más tardías, medievales en cualquier caso (Loveluck, 2004). En estas dark earth aparecen entremezclados todo tipo de materiales (cerámica, hueso, metal, carbón). Una de las posibles causas explicativas de esta mezcla sería la superposición de funciones del espacio, al estar unas veces ocupado por viviendas y otras por huertos o zonas de acumulación de residuos domésticos. La presencia de tierras negras indica en cualquier caso una ocupación intensiva de la zona, que sin duda puede ser definida como de hábitat, aunque no podemos avanzar mucho más en la interpretación. Los datos faunísticos confirman la presencia de especies como la vaca ( $c$. $25 \%$ ), la cabra/oveja (c. $40 \%$ ), y el cerdo (c. 32\%), lo que podría interpretarse como el resultado de una economía más ganadera que agrícola, como se discutirá más adelante, aunque hay que insistir en que la muestra no permite por el momento extraer ningún dato concluyente.

Fase 5: la consolidación de los campos de cultivo. En el sondeo IT-SRM, más al sur y más alejado de la zona de hábitat, la secuencia arqueológica resultó ser más sencilla, compuesta de dos unidades. La superficial es el suelo de uso agrario actual-subactual de cronología moderno-contemporánea, en el que se recogieron abundantes fragmentos de cerámica de todas las cronologías (medieval-moderna-contemporánea). Este nivel cubre un primer horizonte de cultivo de cronología medieval compuesto por sedimentos de acumulación en los que se engloba abundante material arqueológico, principalmente cerámica, restos de teja y escorias de reducción de hierro. De la zona basal, en contacto con la terraza fluvial, se extrajo una muestra (fragmento de hueso) para datar que aportó una fecha entre el X-XII, con mayor probabilidad en la primera mitad del XI (CNA826) (Tabla 2). De este nivel inferior se tomaron muestras de polen que indican el cultivo del cereal, aunque con porcentajes más bajos que los observados en IT-PMR (2,6\% y 2,9\%), que puede deberse a que los cereales son autógamos, por lo que tienen una baja producción y dispersión polínica (López Sáez, López García \& Burjachs, 2003; López Sáez \& López Merino, 2005). Se observa asimismo una cobertura arbórea importante (c. 40\%) con unos porcentajes de castaño (Castanea) cercanos al 10\%. No se encuentran indicios de hongos coprófilos, lo que nos lleva a concluir una falta de presión pastoral o en todo caso tremendamente esporádica. 
La tafonomía es coincidente con lo observado en la prospección superficial en este mismo espacio: alta fragmentación del material arqueológico y alta presencia de cerámica medieval en todos los niveles.

Fase 6: la fijación de la aldea plenomedieval. En las UE007 y 008 (IT-CDR10) se ha identificado un suelo de cabaña, muy cerca de la actual zona habitada (Fig. 10). Fechado a finales del siglo XIII o principios del XIV (DSH2217) (Tabla 2), representa un cambio importante con respecto a las fases de ocupación altomedievales. Si en aquéllas no se aprecian más indicios de estructuras que negativos excavados en el suelo y restos de dark earth, ahora se observa un acondicionamiento previo del espacio de hábitat mediante un empedrado (UE008) y una distribución interna con un lugar reservado para el hogar. Aunque las dimensiones del sondeo no nos han permitido documentar las paredes perimetrales, creemos que la presencia de abundante teja y de este empedrado deben estar relacionadas con unas estructuras de cercamiento de la vivienda también más sólidas, de base pétrea y además en una zona ya plenamente establecida de hábitat. Podemos hablar de casas en el sentido actual de la palabra, asentadas en un espacio netamente delimitado y separado del terrazgo.

Los datos de la fauna nos indican una regresión de la vaca con respecto al período altomedieval $(10 \%)$ y una abundancia de las especies de menor porte, como el cerdo (más del $70 \%)$ o la cabra $(19 \%)^{14}$. En términos económicos podría interpretarse este descenso del vacuno como una consecuencia de la expansión de la actividad agrícola, que deja menos suelos vacantes para dedicar al pasto extensivo. El aprovechamiento de espacios marginales (cabra) se interpreta en este mismo sentido.

Fase 7: una inundación que arrasa la aldea. Compuesta por las UE004, 005, 006 de la IT-CDR10, UE006 y 007 IT-PMR10 y 005 de la IT-PLO10 ${ }^{15}$. Se trata de una serie de niveles y canales de paleoavenida del arroyo de San Romano (Figs. 8 y 10), que por los materiales de las fases infrayacentes y suprayacentes sabemos que se produjo en al-

14. Aunque en este grupo se incluyen todos los ovicaprinos, la única especie que ha podido identificarse es la cabra.

15. En la campaña arqueológica más reciente (2015) se confirma este evento torrencial y sus consecuencias catastróficas para la aldea medieval en el sondeo IT-MUR, donde se han identificado de nuevo niveles de arroyada entre los que se entremezclan restos de construcciones y diferentes materiales que confirman la adscripción al período medieval de este episodio. Lo más interesante de esta nueva intervención es que se han identificado las áreas dedicadas al cultivo en el momento anterior a la inundación. Los materiales cerámicos recogidos presentan en términos tafonómicos las mismas características que los recuperados en superficies contemporáneas: alta fragmentación y rodamiento. Por ello, concluimos que en estas fechas la aldea ya contaría con un sistema de campos abiertos para el cultivo extensivo con el arado. 
gún momento posterior a los siglos XIII-XIV y anterior al XVI, como veremos más adelante. Estos niveles han sido removidos en etapas posteriores para nivelar el terreno, por lo que su espesor es variable en los diferentes sitios. Gracias a ellos, se han preservado intactas algunas de las fases de ocupación medieval. La horquilla cronológica nos permite fijar este evento torrencial en un momento de cambio climático importante: el arranque de la Pequeña Edad de Hielo. Sabemos por algunas referencias documentales de las devastadoras consecuencias acarreadas por la crecida de algunos ríos en este período, como el Narcea, que a mediados de la decimocuarta centuria arrasó la vega de Soto. También los valles de los ríos Aller, Lena y Caudal sufrirán inundaciones periódicas durante los siglos XIV y XV (Ruiz de la Peña, 1977). Esta inundación podría explicar por qué se funda una villa nueva en la otra orilla del río Trubia en torno al siglo XIV.

FIGURA 10

Planta UE008 de la IT-CDR

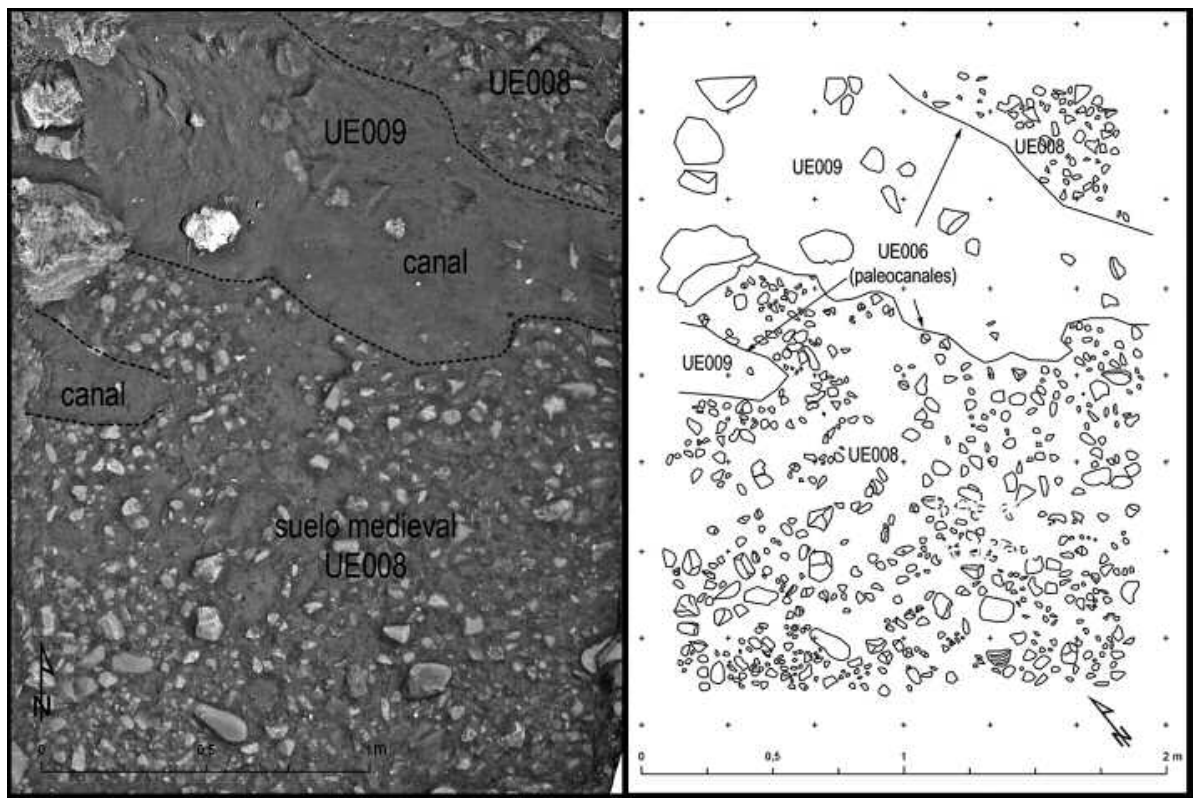

Izquierda: foto cenital; derecha: dibujo de la planta. Pueden apreciarse los paleocanales de inundación que cortan el suelo empedrado de origen medieval. Del hogar sobre la UE008 se extrajo una muestra para ser datada: DSH2217 (siglos XIII-XIV).

Fuente: elaboración propia.

Fase 8: un espacio agrario reconfigurado. La inundación dejó una serie de depósitos de espesor variable que convertirían esta zona en improductiva. No será hasta el siglo XVI cuando detectemos en la proximidad de la aldea un primer indicio de actividad. Una datación procedente de la UE003 del sondeo CDR arroja una cronología del 2。 1469-1635 
cal. d.C. (Tabla 2: DSH2322). En el caso de PMR, la primera UE que se apoya sobre los niveles de la paleoavenida es la 005, en la que se ha encontrado una moneda (4 maravedís de los Reyes Católicos) acuñada y en circulación durante el siglo XVI. Tras estas fechas se retoma la actividad agraria y ya no existen indicios de estructuras de hábitat, lo que indica que se ha producido el cierre definitivo de estos espacios y su uso no cambia hasta la segunda mitad del siglo Xx, cuando estas tierras de labor se convierten en pastizales. En este período se privatizará parte de este espacio por parte de una familia noble, los Muñiz Prada.

En estas mismas cronologías se estaría aterrazando La Güerta de San Romano, tal como se pudo verificar en un último sondeo realizado (IT-PTE) donde se pudo tomar una fecha de la zanja de cimentación del muro en su límite con el río (CNA828, Tabla 2). Esta fecha indica la construcción en algún momento del siglo XVI o posterior. Los análisis químicos de suelos indican índices altos de materia orgánica y nutrientes, valores normales en suelos de cultivo. De este sondeo se tomaron varias muestras sedimentológicas para análisis polínicos. El paleopaisaje inferido indica una cobertura arbórea que sigue siendo baja $(<30 \%)$, en la que predominan los robles, acompañados de arces, abedules, hayas, acebos, tilos y pinos de procedencia regional. Los elementos antrópico-nitrófilos y los antropozoógenos sugieren una escasa presión pastoral y faltan por completo los hongos coprófilos. El dato más interesante es que, al contrario que los primeros suelos de cultivo medievales documentados en otros sondeos, no se detecta la presencia de polen de cereales, lo cual supone un cambio con respecto a la etapa anterior que quizá esté relacionado con la presencia de otro tipo de cultivos.

\subsubsection{Arqueología de los espacios aterrazados: el manso parroquial}

Tres sondeos se realizaron en espacios aterrazados. El anteriormente descrito (IT-PTE), otro en el manso parroquial (MNS) y uno más en el espacio agrario denominado Pando (PND) (Fig. 11).

La principal secuencia documentada procede de El Manso (IT-MNS), elegido porque su topónimo indica que perteneció a la Iglesia (manso era el nombre que se daba en Asturias a los terrenos propios de las parroquias destinados al mantenimiento del clero local en la Edad Media). Ya aparece mencionado en la documentación del siglo XIv ${ }^{16}$. Además es un espacio aterrazado, con una potencia de más de tres metros de rellenos,

16. San Romano de Villanueva [...]. Ha de manso tres días de bues (véase FeRnández Conde, 1987: 124). Estas medidas coinciden con la extensión actual de la parcela. 
lo que ha permitido establecer una secuencia vertical completa del proceso de construcción.

Cabe destacar la localización de un epígrafe, posiblemente romano, en uno de los muros de esta parcela durante la realización de estos trabajos, lo que complementa la escasa información arqueológica que estamos recuperando en la aldea sobre este período (Fernández Fernández, 2014a, 2014b).

Atendiendo a la secuencia estratigráfica obtenida, ya descrita en otros trabajos (Fernández Fernández, 2014a, 2014b), podemos establecer unas horquillas cronológicas para su construcción que dividimos en cinco fases principales.

Fase 1: un primer espacio agrario altomedieval. Sabemos que antes de la construcción de esta terraza existía un suelo de ladera sobre el que en algún momento entre los siglos VII-IX (Tabla 2: DSH2232), con mayor probabilidad en el VIII, ya se encuentra un suelo muy antropizado, con abundantes restos de materia orgánica y fragmentos de cerámicas de tipologías medievales. Todo ello apunta a la existencia de un primer aprovechamiento agrario de este lugar en esas cronologías.

Fase 2: la construcción de una primera terraza. Sobre estos suelos antropizados se aporta un primer relleno (UE005), fechado entre los siglos IX-XII (Tabla 2: CNA824, CNA825, DSH2218), en el que se registran pólenes de cereal, aunque en porcentajes muy bajos, en la línea de lo observado en otros sondeos. Los índices de $\mathrm{C} / \mathrm{N}(8,6)$ se corresponden con los de otros suelos de uso agrario analizados. Sabemos que este sedimento fue aportado desde un lugar cercano (parte alta de la ladera), donde se realizaron otros dos sondeos (VIÑ y FRE), en los que pudo verificarse la alteración del suelo original. La cultura material corrobora la cronología medieval, ya que existe una total correspondencia entre las cerámicas rescatadas de este relleno (UE005) y las observadas en los niveles altomedievales excavados en el entorno de la aldea (UE 8 y 9 de IT-PRM y UE 10 y 11 de IT-CDR).

Fase 3: esta primera terraza aparece sellada por un nivel de sedimento y cantos con cronología bajomedieval, datados entre los siglos XIII-XIV (Tabla 2: DSH2215), que indican un cambio: ¿abandono?

Fase 4: la construcción de una nueva terraza. Sobre el nivel de cantos bajomedieval se volverá a depositar un potente paquete sedimentario rico en cerámica de época moderna (UE004), que casi duplica la altura de la primera terraza medieval. 
Fase 5: la secuencia se cierra con la erección de un último muro de contención, de mampostería (UE003), asociado a niveles (UE001) con materiales moderno-contemporáneos (siglos XIX y XX).

\section{FIGURA 11}

\section{Perfiles estratigráficos de diferentes terrazas agrarias del entorno} de Villanueva de Santo Adriano
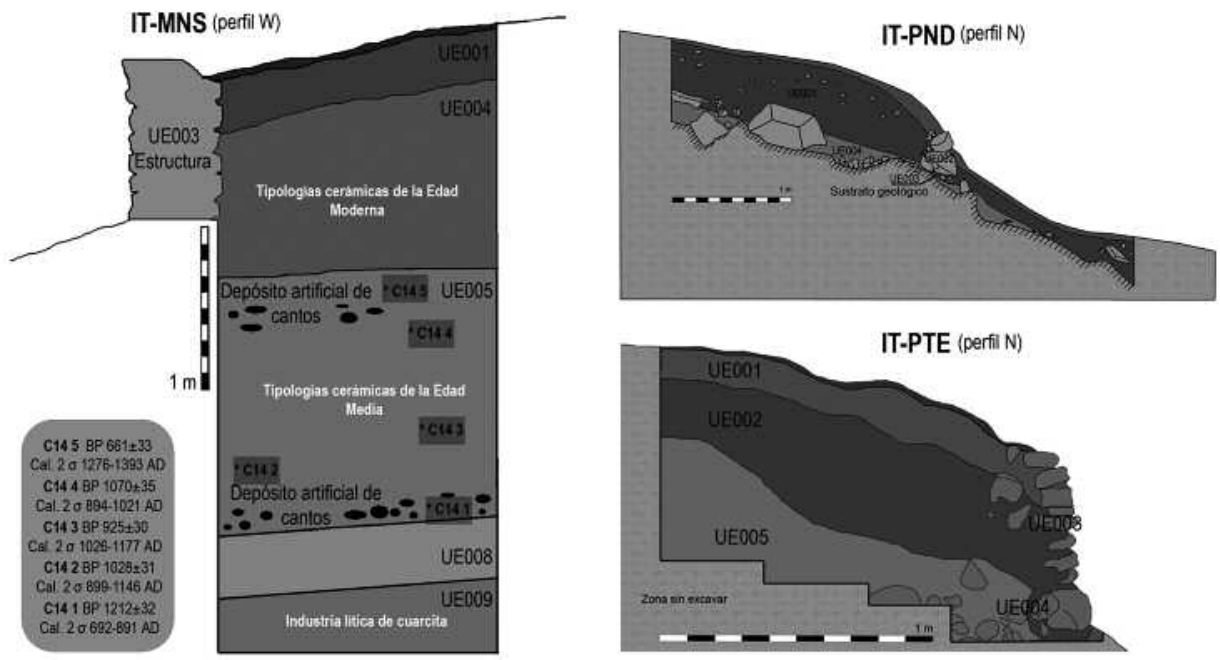

Código de dataciones en Tabla 2: C14-1, DSH2232; C14-2, DSH2218; C14-3, CNA825; C14-4, CNA824; C14-5 (UE6, depósito artificial de cantos), DSH2215.

Fuente: elaboración propia.

En otras intervenciones realizadas se registran también estos mismos ciclos de cambio en el uso del espacio agrario y construcción de terrazas. En el caso de la vega de San Romano (IT-SRM), se ha fechado un primer momento de aprovechamiento agrario entre los siglos X-XI (Tabla 2: CNA826) y la construcción de un muro de aterrazamiento en torno al XVI (IT-PTE, Fig. 11; Tabla 2: CNA828). Otra terraza, en la que también se documenta el cultivo del cereal, ha sido fechada en torno al XVI en el lugar denominado Pando (IT-PND, Fig. 11; Tabla 2: CNA827).

$\mathrm{El}$ análisis de los espacios aterrazados permite establecer tres momentos de importante transformación del espacio agrario de la aldea. Una primera etapa de actividad entre los siglos viII-X, donde encontramos campos de cultivo en el entorno del barrio más antiguo de San Romano (UE9-IT-PMR) y ya se están colonizando espacios en zonas más alejadas, lo que indica una primera presión agraria sobre el entorno muy temprana, que hemos fechado en torno al siglo VIII en El Manso (UE7-IT-MNS). Esta actividad se inten- 
sifica mediante la construcción de una terraza en torno a los siglos X-XI, coincidiendo con la consolidación del hábitat en la aldea de San Romano. Este paisaje parece estabilizarse hasta el siglo XIV, en que encontramos indicios de abandono de algunas de estas estructuras, quizá relacionado con la contracción demográfica de ese siglo, durante el cual los espacios más alejados pudieron cambiar de función, como vimos en Buyera. En el siglo XVI se produce una intensificación agraria que obliga a construir nuevos espacios aterrazados donde antes no existían (como el caso de SRM o PND) o a ampliar y mejorar los ya existentes (como el caso de MNS), que resultaría de dos factores: la introducción de nuevos cultivos procedentes de América y el importante empujón demográfico del período. Finalmente, en los siglos XIX-XX se produce un nuevo crecimiento demográfico que obliga a restaurar y recrecer algunos de estos sistemas de aterrazamientos.

FIGURA 12

\section{Detalle de la terraza excavada IT-PTE}

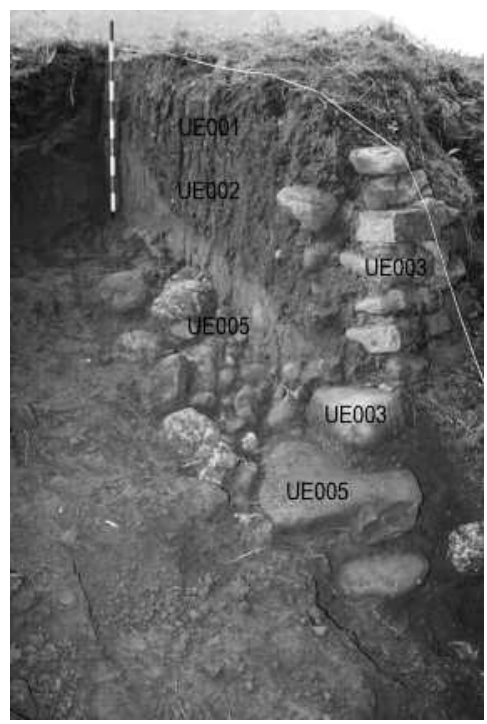

Del relleno de la zanja de cimentación del muro (UE004) se tomó una muestra para datar: CNA828 (siglos XV-XVII).

Fuente: elaboración propia.

\section{CONCLUSIONES}

El análisis de las formas del paisaje, el estudio de la documentación, la toponimia y la excavación arqueológica, tratando todo el territorio aldeano como un único objeto de estudio, nos ha permitido realizar una primera interpretación de la historia de una aldea que continúa habitada desde su momento de formación en la Alta Edad Media. Con es- 
tos datos podemos responder las preguntas de investigación que nos planteábamos en el apartado introductorio, en primer lugar la relativa a la cuestión cronológica: ¿cuándo se produce la génesis de la aldea y su terrazgo?

El primer registro arqueológico de la presencia de un grupo de campesinos que está empezando a transformar con su actividad el paisaje antiguo, roturando campos, cultivando cereal y construyendo estructuras de madera, lo podemos fechar en la Alta Edad Media, en torno a los siglos VIII-X. En el X-XI vemos que el hábitat se intensifica en el entorno de San Romano, se establecen los terrazgos y se construyen las primeras terrazas agrarias en El Manso. Todos estos rasgos conformarán la primera estructura aldeana básica, a partir de la que se irá desarrollando Villanueva.

Respecto de la segunda pregunta de investigación expuesta (¿cómo se produce esta génesis aldeana y qué procesos sociales están detrás?), la fundación a finales de la novena centuria del monasterio de Tunón y el nuevo ritmo de transformaciones en el espacio que se observan a través de la arqueología en los siglos IX-XI no pueden ser interpretados como fenómenos disociados. Por los datos de que disponemos, aunque son por el momento muy parcos, hay actividad anterior a esta fundación, lo que podría indicar que efectivamente hay unas estructuras ¿aldeanas? previas sobre las que se produce la actuación señorial. Es en cualquier caso en el momento de la fundación del monasterio cuando se ve clara la intensificación, tanto en los aprovechamientos agrícolas (construcción de terrazas) como en las zonas de hábitat. La impresión que nos trasladan estos datos es que se están implementando unas estrategias de intensificación de la producción y control político-social (con la creación de un centro de poder local), cuyo resultado final es un paisaje seminal de aldeas concentradas con sus espacios productivos, que en sus rasgos estructurales va a pervivir hasta el presente.

Respecto de la tercera pregunta de investigación (¿cómo han evolucionado y se han ido transformando a lo largo del tiempo estas aldeas y sus espacios agrarios?), sabemos que en los siglos XIII-XIV el hábitat está consolidado sobre el solar del actual barrio de San Romano, con casas de suelo empedrado, hogares e indicios de cubiertas techadas con teja. Posteriormente una inundación destruye San Romano y parte de sus terrazgos quedan estériles. Este evento podría estar relacionado con la aparición de una villa nueva en la otra orilla del río Trubia, que aparece mencionada por primera vez a finales del XIV y que con el tiempo pasará a denominar el conjunto aldeano integrando el núcleo original (San Romano) como un barrio más. Será a partir de este momento cuando arranque la implantación de familias nobiliarias en la aldea. La parentela menor de los Muñiz Prada y las elites campesinas se irán asentando en el barrio de San Romano, que concentra en él la arquitectura de las elites. 
En conclusión, hemos conseguido dar respuesta a un primer y básico cuestionario de investigación, pero son todavía muchas las preguntas que quedan pendientes de ser resueltas: ¿cómo era la estructura interna de las aldeas altomedievales y cómo se distribuía el terrazgo?, ¿qué capacidad productiva tenían estas tierras?, ¿qué cantidad de renta podrían generar, cómo y quién la captaba?, ¿hubo estratificación interna entre el grupo campesino medieval?, ¿cuál era su capacidad de agencia? Cuestiones que tendrán que ir respondiéndose a medida que continúe esta investigación, de la que tan solo se están sentando unas primeras bases.

\section{AGRADECIMIENTOS}

A los evaluadores anónimos de la revista Historia Agraria, que con sus críticas, comentarios y sugerencias han ayudado a mejorar notablemente el texto. A Chris Wickham y Margarita Fernández Mier por sus aportaciones.

La elaboración de este estudio ha contado con el apoyo de una ayuda postdoctoral del programa Marie Curie-«Clarin-COFUND» del Principado de Asturias [ACA1 4-08] y se enmarca dentro de los siguientes proyectos de investigación: «La formación de los paisajes del Noroeste Peninsular durante la Edad Media (siglos V al XII)» (Ref. HAR201021950-CO3-03); «Poder central y poderes locales entre la Atigüedad Tardía y la Alta Edad Media. 400-900 D.C. El Norte de Hispania y su contexto europeo» (HAR2013-47889C3-3-P), financiados por la Secretaría de Estado de I+D+i del Ministerio de Economía y Competitividad. Otras entidades colaboradoras: Consejería de Medio Ambiente del Principado de Asturias (Dirección Gral. de Montes y Política Forestal). Equipo técnico: Marta Moreno García (arqueofauna); J. Antonio López Sáez, Sebastián Pérez Díaz y Begoña Hernández Beloqui (paleobotánica).

\section{REFERENCIAS}

Ballesteros, P. (2002). A paisaxe agraria de Elviña: Os elementos e as formas. Santiago de Compostela: Laboratorio de Patrimonio, Paleoambiente e Paisaxe, Instituto de Investigacions Tecnoloxicas, Universidade de Santiago de Compostela. (CAPA, 15).

BAllesteros, P. (2003). La arqueología en la gasificación de Galicia. 17: El paisaje agrario. Santiago de Compostela: Laboratorio de Patrimonio, Paleoambiente e Paisaxe, Universidade de Santiago de Compostela. (CAPA, 18).

BALLESTERos, P. (2010). La arqueología rural y la construcción de un paisaje agrario medieval: El caso de Galicia. En H. KIrChNeR (Ed.), Por una arqueología agraria: Pers- 
pectivas de investigación sobre espacios de cultivo en las sociedades medievales hispánicas (pp. 25-39). Oxford: Archaeopress. (BAR International series, 2062).

BALlesteros, P. \& Blanco, R. (2009). Aldeas y espacios agrarios altomedievales en Galicia. En J. A. QuiRós (Ed.), The Archaeology of Early MedievalVillages in Europe (pp. 115-135). Bilbao: Universidad del País Vasco.

Ballesteros, P., Criado, F. \& Andrade, J. M. (2006). Formas y fechas de un paisaje agrario de época medieval: A Cidade da Cultura en Santiago de Compostela. $A r-$ queología espacial, (26), 193-225.

Ballesteros, P., Kirchner, H., Fernández Mier, M., Ortega, J., Quirós, J. A., Retamero, F., Sitjes, E., Torró, J. \& Vigil-Escalera, A. (2010). Por una arqueología agraria de las sociedades medievales hispánicas: Propuesta de un protocolo de investigación. En H. Kirchner (Ed.), Por una arqueología agraria: Perspectivas de investigación sobre espacios de cultivo en las sociedades medievales hispánicas (pp. 185-202). Oxford: Archaeopress. (BAR International series, 2062).

BARCEló, M. (1988). Arqueología medieval: En las afueras del «medievalismo». Barcelona: Crítica.

BEUG, H. J. (2004). Leiffaden der Pollenbestimmung für Mitteleuropa und angrenzende Gebiete. München: Dr. Friedrich Pfeil.

BlaAuw, M. (2010). Methods and Code for "Classical" Age-Modeling of Radiocarbon Sequences.. Quaternary Geochronology, (5), 512-518.

BRonk Ramsey, C. (2009). Bayesian Analysis of Radiocarbon Dates. Radiocarbon, 51 (1), 337-360.

Burjachs, F., López Sáez, J. A. \& Iriarte, M. J. (2003). Metodología arqueopalinológica. EN R. Buxó \& R. PiQué (Eds.), La recogida de muestras en arqueobotánica: Objetivos y propuestas metodológicas (pp. 11-18). Barcelona: Museu d'Arqueología de Catalunya.

Fernández Conde, F. J. (1987). La Iglesia de Asturias en la Baja Edad Media: Estructuras económico-administrativas. Oviedo: Instituto de Estudios Asturianos.

Fernández Conde, F. J. \& Pedregal, M. A. (1995-1996). Santo Adriano de Tunón: Historia de un territorio en los siglos de transición. Asturiensia Medievalia, (8), 79-110.

FERNÁNDEZ FERNÁNDEZ, J. (2014a). Estudios multiescalares sobre la alta edad media en el Valle del Trubia (Asturias, España). Oviedo: Universidad de Oviedo.

FERNÁNDEZ FERNÁNDEZ, J. (2014b). Aproximación arqueológica a la génesis y evolución del poblamiento medieval en un territorio de media montaña (bajo Valle del Trubia, concejos de Proaza, Santo Adriano y Oviedo). En Excavaciones arqueológicas en Asturias (pp. 331-342). Vol. 7. Oviedo: Consejería de Cultura del Principado de Asturias.

FERNÁNDEZ FERNÁNDEZ, M. (2014). Las Respuestas Generales del Catastro del Marqués de la Ensenada en el concejo de Santo Adriano. Cuadiernu, (2), 5-49. 
Fernández Hevia, J. M. \& Fernández Mier, M. (1994). Notas metodológicas para el análisis microespacial de un despoblado medieval de montaña: El caso de Presorias (Teberga, Asturies). Actas del IV Congreso de Arqueología Medieval Española, t. 2, 493498.

Fernández Hevia, J. M. \& Fernández Mier, M. (1998). Un microespacio en la montaña asturiana: Presorias. Arqueología y territorio medieval, (5), 91-108.

FERNÁNDEZ Mier, M. (1999). Génesis del territorio en la Edad Media. Arqueología del paisaje y evolución histórica en la montaña asturiana: El valle del río Pigüeña. Oviedo: Universidad de Oviedo.

Fernández Mier, M. (2010). Campos de cultivo en la Cordillera Cantábrica: La agricultura en zonas de montaña. En H. KIRCHNER (Ed.), Por una arqueología agraria: Perspectivas de investigación sobre espacios de cultivo en las sociedades medievales hispánicas (41-59). Oxford: Archaeopress. (BAR International series, 2062).

Fernández Mier, M., Aparicio, P., González Álvarez, D., Fernández Fernández, J. \& Alonso, P. (2013). Proyecto de investigación: La formación de los paisajes agrarios del noroeste peninsular durante la Edad Media (siglos v al XII). Debates de Arqueología Medieval, (3), 359-374.

Fernández Mier, M., Fernández Fernández, J., Alonso, P., López Sáez, J. A., PéRez Díaz, S. \& Hernández Beloqui, B. (2014). The Investigation of Currently Inhabited Villages of Medieval Origin: Agrarian Archaeology in Asturias (Spain). Quaternary International, (346), 41-55.

FERNÁNDEZ OCHOA, C. \& Gil SENDINo, F. (2007). La etapa final de Roma en Hispania: La villa de Veranes (Gijón, Asturias). En J. A. FernándeZ-Tresguerres (Ed.), $A s-$ tures y romanos en el Principado de Asturias: Nuevas aportaciones y perspectivas (pp. 133-148). Oviedo: Real Instituto de Estudios Asturianos.

García de Castro, C. y Ríos, S. (1988). Los castillos de Proaza. Arqueologia y territorio medieval, (5), 69-90.

García Fernández, J. (1988). Sociedad y organización del espacio tradicional de Asturias. Gijón: Silverio Cañada.

García Larragueta, S. (1962). Coleccion de documentos de la Catedral de Oviedo. Oviedo: Instituto de Estudios Asturianos.

Guilaine, J. (Ed.) (1991). Pour une archéologie agraire. Paris: Armand Colin.

LEwIS, C. (2007). New Avenues for the Investigation of Currently Occupied Medieval Rural Settlement: Preliminary Observations from the Higher Education Field Academy. Medieval Archaeology (51), 133-63.

López FernándeZ, V. (1900). Santo Adriano. En F. Canella \& O.Bellmunt (Eds.), Asturias, vol. III (pp. 171-180). Gijón: Fototip. y Tip. de O. Bellmunt. 
López Sáez, J. A. \& López Merino, L. (2005). Precisiones metodológicas acerca de los indicios paleopalinológicos de agricultura en la Prehistoria de la Península Ibérica. Portugalia, (26), 53-64.

López Sáez, J. A., López García, P. \& Burjachs, F. (2003). Arqueopalinología: Síntesis crítica. Polen, (12), 5-35.

LoveluCK, C. (2004). Terres Noires and Early Medieval Rural Settlement Sequences: Conceptual Problems, Descriptive Limitations and Deposit Diversity. En L.VERSLYPE \& R. Brulet (Eds.), Terres Noires-Dark Earth. Actes de la table ronde internationale tenue à Louvain-la-Neuve, les 09 et 10 novembre 2001 (pp. 43-96). Louvain-laNeuve: Université Catholique de Louvain.

MACPHAIL R. I. \& LINDERHOLM, J. (2004). "Dark Earth": Recent Studies of "Dark Earth" and "Dark-Earth-like" Microstratigraphy in England, UK. En L. VersLYPE \& R. BRULET (Eds.), Terres Noires-Dark Earth. Actes de la table ronde internationale tenue à Louvain-la-Neuve, les 09 et 10 novembre 2001 (pp. 35-42). Louvain-la-Neuve: Université Catholique de Louvain.

MARCos, A. (1999). Estructuras de la propiedad en la época moderna: Evolución y variantes peninsulares. En R. Robledo, E. ToriJano, S. DE Dios \& J. INFANTE (Coords.), Historia de la propiedad en España, siglos XV-XX: Encuentro interdisciplinar, Salamanca, 3-6 de junio de 1998 (pp. 113-162). Salamanca: Centro de Estudios Registrales.

MonTES, R. (2015). Intervenciones arqueológicas realizadas con motivo del seguimiento de las obras de saneamiento y EDAR de Proaza y Santo Adriano. Cuadiernu, (3), 99125.

Moore, P. D., WebB, J. A. \& Collinson, M. E. (1991). Pollen Analysis. Oxford: Blackwell Science.

Quirós, J. A. (2009). Arqueología de los espacios agrarios medievales en el País Vasco. Hispania, 69 (233), 619-652.

QuiRós, J. A. (2010). De la arqueología agraria a la arqueología de las aldeas medievales. En H. Kirchner (Ed.), Por una arqueología agraria: Perspectivas de investigación sobre espacios de cultivo en las sociedades medievales hispánicas (pp. 11-22). Oxford: Archaeopress. (BAR International series, 2062).

Quirós, J. A. (2012). Arqueología del campesinado medieval: La aldea de Zaballa. Bilbao: Universidad del País Vasco.

Quirós, J. A. \& Vigil-Escalera, A. (2006). Networks of PeasantVillages between Toledo and Uelegia Alabense, Northwestern Spain ( $\mathrm{V}-\mathrm{X}^{\text {th }}$ Centuries). Archeologia Medievale, (33), 79-128.

ReILle, M. (1999). Pollen et spores d'Europe et d'Afrique du nord. Marseille: Laboratoire de Botanique Historique et Palynologie.

Reimer, P. J. et al. (2009). IntCal09 and Marine09 Radiocarbon Age Calibration Curves, 0-50,000 Years cal BP. Radiocarbon, 51 (4), 1111-1150. 
Requejo, O. (2004). El registro arqueológico en el territorio de Cangas de Onís: Producciones cerámicas tardías y altomedievales. Espacio, tiempo y forma. Serie I: Prehistoria y arqueología, (16-17), 479-539.

Ruiz de la PeÑa, J. I. (1977). Historia de Asturias: Baja Edad Media. Salinas: Ayalga.

RuIz de la PeÑA, J. I. (1981a). Las "polas» asturianas en la Edad Media: Estudio y diplomatario. Oviedo: Universidad de Oviedo.

Ruiz de la PeÑa, J. I. (1981b). Fueros agrarios asturianos del siglo XIII. Asturiensia medievalia, (4), 131-196.

Ruiz de la Peña, J. I. \& Beltrán, M. S. (2009). Señorío y vasallaje en la Asturias medieval: El Libro de las jurisdicciones de la mitra ovetense (1385-1386). Oviedo: Real Instituto de Estudios Asturianos.

Ruiz de la PeÑa, J. I., Beltrán, M. S. \& Álvarez FernándeZ, M. (2006). Las villas nuevas de Asturias: Siglos XII-XIv. Boletín Arkeolan, (14), 115-138.

RuIz Del ÁRBol, M. (2005). La arqueología de los espacios cultivados. Terrazas y explotación agraria romana en un área de montaña: La sierra de Francia (Salamanca). Madrid: Consejo Superior de Investigaciones Científicas.

Torrente, M. I. (1986). Términos agrarios en el Medievo asturiano (siglos X-XII). Asturiensia Medievalia, (5), 75-87.

Valdés, B., Díez, M. J. \& Fernández, I. (Eds.) (1987). Atlas polínico de Andalucía occidental. Sevilla: Universidad de Sevilla.

VAN GeEL, B. (2001). Non pollenpalynomorphs. En J. P. SMOL, H. J. B. BiRKS \& W. M. LAST (Eds.), Tracking Environmental Change Using Lake Sediments. 3:Terrestrial, Algal, and Siliceous Indicators (pp. 99-119). Dordrecht: Kluwer Academic.

Vigil-EsCALERA, A. (2003). Arquitectura de tierra, piedra y madera en Madrid (ss. V-IX d. C.): Variables materiales, consideraciones sociales. Arqueología de la Arquitectura, (2), 287-291.

VigIL-EsCALERA, A. (2007). Granjas y aldeas altomedievales al norte de Toledo (450-800 d. C.). Archivo Español de Arqueología, (80), 239-284.

Vigil-EsCALERA, A. (2010). Formas de parcelario en las aldeas altomedievales del Sur de Madrid: Una aproximación arqueológica preliminar. En H. KIRCHNER (Ed.), Por una arqueología agraria: Perspectivas de investigación sobre espacios de cultivo en las sociedades medievales hispánicas (pp. 1-9). Oxford: Archaeopress. (BAR International series, 2062). 